\title{
Inflammatory and oxidative pathways are new drug targets in multiple episode schizophrenia and leaky gut, Klebsiella pneumoniae, and C1q immune complexes are additional drug targets in first episode schizophrenia
}

Michael Maes, M.D., Ph.D. ${ }^{a, b, c}$, Aristo Vojdani, Ph.D. ${ }^{\text {de,f }}$, Sunee Sirivichayakul, Ph.D. ${ }^{g}$, Decio S. Barbosa, Ph.D. h, Buranee Kanchanatawan, M.D. ${ }^{a}$

${ }^{a}$ Department of Psychiatry, Faculty of Medicine, Chulalongkorn University, Bangkok, Thailand

${ }^{\mathrm{b}}$ Department of Psychiatry, Medical University of Plovdiv, Plovdiv, Bulgaria

${ }^{\mathrm{c}}$ IMPACT Strategic Research Center, Deakin University, Geelong, Australia

${ }^{\mathrm{d}}$ Immunosciences Lab., Inc, Los Angeles, CA, USA.

${ }^{\text {e }}$ Cyrex Labs, LLC, Phoenix, AZ, USA.

${ }^{\mathrm{f}}$ Department of Preventive Medicine, Loma Linda University, Loma Linda, CA, USA.

g Faculty of Medicine, Chulalongkorn University, Bangkok, Thailand

h Health Sciences Graduate Program, Health Sciences Center, State University of Londrina, Londrina, PR, Brazil

Corresponding author:

Prof. Dr. Michael Maes, M.D., Ph.D.

IMPACT Strategic Research Center

Barwon Health

Deakin University

Geelong, Vic

Australia

dr.michaelmaes@hotmail.com

https://scholar.google.co.th/citations?user=1wzMZ7UAAAAJ\&hl=th\&oi=ao

Michael Maes: dr.michaelmaes@hotmail.com

Aristo Vojdani: drari@msn.com

Sunee Sirivichayakul: Sunee.S@chula.ac.th

Decio S. Barbosa: sabbatini2011@hotmail.com

Buranee Kanchanatawan: drburanee@gmail.com 


\begin{abstract}
Recently, a breakdown of paracellular and vascular pathways and activated neuroimmune and oxidative pathways were established in (deficit) schizophrenia. The aim of the current study was to delineate a) the differences in these pathways between stable phase, first (FES) and multiple (MES) episode schizophrenia, and b) the pathways that determine the behavioral-cognitivephysical-psychosocial (BCPS)-worsening in FES/MES. This study included 21 FES and 58 FES patients and 40 healthy controls and measured indicants of serum IgA to C1q, and leaky gut, immune activation, and oxidative stress toxicity (OSTOX) biomarkers. We constructed a BCPSworsening index by extracting a latent vector from symptomatic, neurocognitive, and quality of life data. FES patients showed significantly higher IgA to $\mathrm{C} 1 \mathrm{q}$, cadherin, catenin, plasmalemma vesicle-associated protein, and $\operatorname{IgA} / \operatorname{IgM}$ to Gram-negative bacteria than FES patients and controls. In FES patients, the BCPS-worsening score was predicted (48.7\%) by IgA to Klebsiella pneumoniae and lowered paraoxonase 1 activity. In MES patients, the BCPS-worsening score was explained $(42.7 \%)$ by increased tumor necrosis factor- $\alpha$, OSTOX, and number of episodes. In schizophrenia, $34.0 \%$ of the variance in the BCPS-worsening score was explained by IgA to $K$. pneumoniae, OSTOX, and number of episodes. Increased IgA to $K$. pneumoniae was the single best predictor of residual psychotic symptoms in FES and MES. This study delineated different mechanistic processes in FES, including breakdown of adherens junctions, bacterial translocation, and $\mathrm{Clq}$ circulating immune complexes; and FES, including immune and oxidative stress neurotoxic pathways. FES and MES comprise different staging subtypes, i.e., FES and MES with and without worsening.
\end{abstract}

Key words: deficit schizophrenia, neuro-immune, inflammation, oxidative and nitrosative stress, antioxidants, biomarkers, $\operatorname{IgM}$, autoimmune 


\section{INTRODUCTION}

Recently, we built a new reliable and replicable, data-driven model of schizophrenia, namely a nomothetic network, which reflects the effects of risk and resilience factors and adverse outcome pathways (AOPs) on the cognitome, symptomatome and phenomenome of schizophrenia [1]. The symptomatome of schizophrenia can best be conceptualized as a latent vector, extracted from various symptom domain scores, namely psychosis, hostility, excitation, and mannerism (PHEM), negative symptoms, psychomotor retardation (PMR), and formal thought disorders (FTD) [1-3]. All these symptom domains are manifestations of a single underlying trait, namely overall severity of symptoms of schizophrenia (OSOS), which determines to a large extent its symptomatic manifestations [1-3].

The cognitome (defined as the aggregate of cognitive dysfunctions) of schizophrenia can best be conceptualized as a latent vector extracted from different neurocognitive dysfunctions including impairments in recall, semantic and episodic memory, strategy use, executive functions, visual sustained attention, attention set-shifting, rule acquisition, and emotional recognition [1,4-7]. This latent vector was computed using various probes of a) the Cambridge Neuropsychological Test Automated Battery [8], and b) the Consortium to Establish a Registry for Alzheimer's disease [1,9,10]. Impairments in those neurocognitive probes are manifestations of a single underlying trait, namely a Generalized Cognitive Decline (G-CoDe), which determines to a large extent all its cognitive manifestations [1].

Both OSOS and G-CoDe are strongly associated with the phenomenome of schizophrenia (defined as the self-description of illness features by the patient) as assessed using the self-rated World Health Organization Quality of Life Instrument-Abbreviated version (WHO-QoL-BREF) [11]. The latter assesses physical health, psychological health, and social and environmental responsible behaviors [1]. We found that G-CoDe and OSOS explain $40.9 \%$ of the variance in a LV extracted from those 4 WHO-QoL-BREF domains, reflecting an overall decline in HR-QoL (OD-QoL) [1,5]. Nevertheless, there are no data whether there are differences in G-CoDe, OSOS, and OD-Qol between patients with first episode schizophrenia (FES) and those with multiple episode schizophrenia (MES).

Schizophrenia patients with the deficit syndrome show significantly higher OSOS and lower G-CoDe and OD-QoL scores as compared with patients without the deficit syndrome $[1,2,7,10,12-14]$. Previously [15], deficit schizophrenia was conceptualized as a schizophrenia subtype characterized by negative symptoms, although we delineated that not only negative but also PHEM symptoms, PMR, FTD, and cognitive impairments significantly shape and model deficit schizophrenia [12,13]. Nevertheless, there are no data on the associations between the deficit syndrome and MES and FES. The case definitions of the deficit syndrome as conceptualized by Kirkpatrick et al. [15] and Kanchanatawan et al. [12,13], were based on negative symptoms and all symptom domains, respectively. Nevertheless, our recent studies show that not only OSOS but also changes in G-CoDe and OD-QoL should be used to compute a more comprehensive behavioral-cognitive-physical-psychosocial (BCPS) worsening index $[1,4,5]$.

There is now evidence that schizophrenia, deficit schizophrenia, OSOS, and/or the GCoDe are characterized by immune activation, increased levels of acute phase reactants and complement factors, and increased neurotoxic potential [1,4,16-18]. Firstly, schizophrenia is accompanied by activated immune-inflammatory pathways as demonstrated by a) activation of the inflammatory response system (IRS) including increased levels of tumor necrosis factor- $\alpha$ (TNF- $\alpha$ ), interleukin-6 (IL-6), macrophage inflammatory protein-1 (MIP-1), and CCL11 or 
eotaxin; b) activation of the compensatory anti-inflammatory system (CIRS) as indicated by increased soluble interleukin (IL)-1 receptor antagonist (sIL-1RA), sIL-2R, and IL-10 levels; c) increased IgM levels directed to zonulin indicating increased leaky gut (gut permeability); and d) activation of the indoleamine-2/3-de-oxygenase and the tryptophan catabolite (TRYCAT) pathway as indicated by increased IgA levels directed to noxious tryptophan catabolites including picolinic acid (PA), xathurenic acid (XA), and 3-hydroxykynurenine [1,10,14,17-25].

Secondly, CCL11, IgA to TRYCATs, and increased oxidative stress toxicity (OSTOX), as indicated by increased lipid hydroperoxides $(\mathrm{LOOH})$, malondialdehyde (MDA), and advanced oxidation protein products, predict a large part of the variance in OSOS and the G-CoDe $[1,4,7,26]$. Moreover, OSOS and cognitive deficits are predicted by lowered antioxidant defenses including sulfhydryl (-SH) groups, total radical-trapping antioxidant parameter (TRAP), and activity of paraoxonase 1 (PON1), an anti-inflammatory and antioxidant enzyme [7]. Furthermore, OSOS and cognitive deficits are also associated with lowered IgM responses to oxidative specific epitopes (OSEs), which are part of the innate CIRS and display antiinflammatory housekeeping properties and constitute a first line defense against bacterial infections [27]. Finally, OSOS, G-CODe, and the deficit syndrome are characterized by an increased breakdown of the paracellular and vascular pathways, as assessed with IgA levels to occludin, claudin-5, E-cadherin, catenin, and plasmalemma vesicle associated protein (PLVAP), with increased bacterial translocation, as assessed with $\operatorname{IgA} / \operatorname{IgM}$ levels to the LPS of Gramnegative bacteria [25,28]. Nevertheless, there are no data whether these neurotoxic and protective pathways are differentially associated with the stable phase of FES or MES and whether these pathways may impact BCPS-worsening in those patients. There are some data that drug-naïve patients with first episode psychosis (FEP) show signs of a "mild cytokine storm" with a greater IRS than CIRS response, which additionally predicts a worse outcome to treatment [29]. Moreover, other studies show activated IRS/CIRS pathways in FEP [29]. Interestingly, FES is accompanied by increased levels of intestinal biomarkers including anti-Saccharomyces cerevisiae, antigliadin, transglutaminase 2, and anti-deamidated gliadin peptide antibodies [31].

Hence, the current study was carried out to delineate a) the differences in the abovementioned neurotoxic and protective pathways and C1q circulating immune complexes between stable phase, FES and MES, and b) the specific pathways that determine a newly constructed score which reflects BCPS-worsening in FES/MES.

Subjects and Methods.

Participants

In this case-control study we included Thai individuals with schizophrenia and healthy controls of both sexes and aged 18-65 years. Schizophrenia patients were all outpatients recruited at the Department of Psychiatry, Faculty of Medicine, Chulalongkorn University, Bangkok, Thailand. They all met the diagnostic criteria for schizophrenia of the DSM-IV-TR and were in a clinically stable phase of illness for at least one year. The controls are apparently healthy individuals who were recruited by word of mouth from the same catchment area (Bangkok city, Thailand). We registered the number of psychosis and made the diagnosis of FES and MES according to DSM-5 criteria. As such, we included schizophrenia patients with FES or MES who were in partial or full remission. In addition, we made the diagnosis of deficit schizophrenia according to the Schedule for the Deficit Syndrome (SDS) [15].

We excluded schizophrenia patients with a current or lifetime diagnosis of other axis-I diagnoses according to DSM-IV-TR or DSM-5 criteria, including major depressive disorder, 
bipolar disorder, autism, substance use disorders (except tobacco use disorder), and psychoorganic disorders. We excluded schizophrenia patients and controls with a) neurodegenerative and neuroinflammatory disorders, such as multiple sclerosis, Alzheimer's and Parkinson's disorder; b) immune and autoimmune disorders including chronic obstructive pulmonary disease, rheumatoid arthritis, diabetes, and inflammatory bowel disease; c) alcohol abuse; d) current or lifetime treatment with immunomodulatory drugs including immunosuppresiva and glucocorticoids; and e) treatment with therapeutical dosages of antioxidant supplements or omega-3 polyunsaturated fatty acids. In addition, pregnant and lactating women were excluded. Healthy controls with a current or lifetime diagnosis of DSM-IV-TR / DSM-5 axis 1 diagnoses and/or a family history of psychosis were not allowed to participate.

All participants and their guardians (parents or other close family members) gave written informed consent prior to participation in this study. The study was conducted according to Thai and international ethics and privacy laws. Approval for the study was obtained from the Institutional Review Board of the Faculty of Medicine, Chulalongkorn University, Bangkok, Thailand (No 298/57), which is in compliance with the International Guideline for Human Research protection as required by the Declaration of Helsinki, The Belmont Report, CIOMS Guideline and International Conference on Harmonization in Good Clinical Practice (ICH-GCP).

\section{Methods}

A senior psychiatrist specialized in schizophrenia completed a comprehensive clinical interview comprising socio-demographic and clinical data. The senior psychiatrist employed the Mini-International Neuropsychiatric Interview (M.I.N.I.) in a validated Thai translation [32] and made the diagnosis of MES or FES (using DSM-5 criteria) and deficit or non-deficit schizophrenia (using the SDS). The same days the senior psychiatrist also rated the Positive and Negative Syndrome Scale (PANSS) [33]; the Scale for the Assessment of Negative Symptoms (SANS) [34]; the Brief Psychiatric Rating Scale (BPRS) [35]; and the Hamilton Depression (HDRS) [36]. As explained previously [1], we calculated z unit-weighted composite scores which reflect the severity of psychosis, hostility, excitation, mannerism, negative symptoms, PMR, and FTD [28]. Consequently, we extracted the first latent vector (LV) from these scores reflecting overall severity of symptoms (OSOS) [1-3].

The same day, neurocognitive testing was performed by a well-trained clinical research assistant with a master's degree in mental health. Four CERAD tests were scored, namely the Word List Memory (WLM), Word List True Recall (Recall), the Verbal Fluency Test (VFT), and the Mini Mental State Examination (MMSE). The same research assistant assessed key outcome measures for CANTAB Research Suite Tests [8], namely Paired-association learning total errors adjusted (PAL-TEA), rapid visual information process test A' Prime (RVP_A), spatial working memory between errors (SWM-BE) and SWM strategy (SWM-STR), One touch stockings of Cambridge probability solved on first choice (OTS-PSOFC), Intra/extradimensional set shifting total errors adjusted (IED_TEA), and Emotional recognition test mean overall response latency (ERT-MORL). Consequently, we extracted the first LV from these 11 tests named Generalized Cognitive Deficit (G-CoDe) [4].

The same day, all subjects scored the WHO-QoL-BREF [11]. This scale assesses HRQoL in four domains: physical health, psychological health, relationships, and environment. Consequently, a LV was extracted from these 4 scores reflecting OD-QoL [4]. We also made the diagnosis of tobacco use disorder (TUD) according to DSM-IV-TR criteria. Body mass index (BMI) was computed as body weight divided by body length (in meter) squared. 
Assays.

Blood was sampled at 8.00 a.m. after an overnight fast and thawed for assay. All assays were conducted in one and the same run by the same operator who was blinded to the clinical results. As described previously [10], ELISA tests were employed to assay the plasma titers of immunoglobulins (Ig) A (IgA) directed against the tryptophan catabolites xanthurenic acid (XA) (Acros), picolinic acid (PA) (Acros), 3-OH-kynurenine (3HK) (Sigma), linked to $20 \mathrm{mg}$ BSA (ID Bio). Optical densities (ODs) were measured at $450 \mathrm{~nm}$ using Varioskan Flash (Thermo Scientific). Consequently, we computed a $\mathrm{z}$ unit-based composite score reflecting the neurotoxic effects of an activated TRYCAT pathway as $\mathrm{z}$ score of XA (zXA) $+\mathrm{zPA}+\mathrm{z} 3 \mathrm{HK}$ $(\mathrm{zXA}+\mathrm{PA}+3 \mathrm{HK})$. Serum levels of CCL11, IL-6, IL-10, TNF- $\alpha$, MIP, and soluble IL-1 receptor antagonist (sIL-1RA) (R\&D Systems, Inc, Minneapolis, MN, USA) were measured using the Bio-Plex ${ }^{\circledR} 200$ System (Bio-Rad Laboratories, Inc.) as reported previously [22,24].

We assayed 3 oxidative stress and 3 antioxidant (3ANTIOX) biomarkers, namely LOOH, MDA, AOPP, -SH groups, PON1 activity and TRAP as explained previously [26]. "MDA levels were measured through complexation with two molecules of thiobarbituric acid using MDA estimation through high-performance liquid chromatography (HPLC Alliance e2695, Waters', Barueri, SP, Brasil). AOPP was quantified in a microplate reader (EnSpire, Perkin Elmer, USA) at a wavelength of $340 \mathrm{~nm}$. LOOH was quantified by chemiluminescence in a Glomax Luminometer (TD 20/20), in the dark, at $30{ }^{\circ} \mathrm{C}$ for $60 \mathrm{~min}$. TRAP was evaluated in a microplate reader (Victor X-3, Perkin Elmer, USA). -SH groups were evaluated in a microplate reader (EnSpire ${ }^{\circledR}$, Perkin Elmer, USA) at a wavelength of $412 \mathrm{~nm}$. The substrates used to assess PON1 activity were phenyl acetate (PA, Sigma, USA) under high salt condition and CMPA (Sigma, USA), which is an alternative to the use of the toxic paraoxon. PON1 activities were determined by the rate of hydrolysis of CMPA (CMPAase) as well as by the rate hydrolysis of phenyl acetate under low salt condition. Analysis were conducted in a microplate reader (EnSpire, Perkin Elmer, USA). Consequently, we computed a $\mathrm{z}$ unit-weighted composite score reflecting oxidative stress $(3 \mathrm{OX})$ as $\mathrm{z} \mathrm{LOOH}+\mathrm{z}$ MDA $+\mathrm{z}$ AOPP and a $\mathrm{z}$ score reflecting antioxidant capacity 3 (ANTIOX) as $\mathrm{z} \mathrm{SH}+\mathrm{z}$ PON1 $+\mathrm{z}$ TRAP. In addition, we computed a 3OX/3ANTIOX ratio as $\mathrm{z} 3 \mathrm{OX}-\mathrm{z} 3 \mathrm{ANTIOX}$.

Subsequently, we computed a neurotoxicity index as z TNF- $\alpha+$ zIL-6 + zMIP + $\mathrm{zXA}+\mathrm{PA}+3 \mathrm{HK}+\mathrm{zLOOH}+\mathrm{zMDA}+\mathrm{zAOPP}$. CCL11 was not included in this index to allow for the additional effects of this chemokine [24]. Finally, we also computed an immune activation index as all $\mathrm{z}$ values in the neurotoxicity index $+\mathrm{zIL}-10+\mathrm{zCCL} 11+\mathrm{zsIL}-1 \mathrm{RA}$ $+\mathrm{zCCL} 11$.

For assays of the serum concentration of $\mathrm{C} 1 \mathrm{q}$ binding immune complexes we purchased goat anti-complement C1q-affinity pure Cat\# GWB-757295 from Genway Biotech Inc. (San Diego, CA 92121, USA). Alkaline phosphatase conjugated affinity pure goat anti-human IgA $(\alpha), F C \mu, F C \gamma$, were purchased from Jackson-Immuno Research (West Grove, PA USA). Microwell ELISA plates were coated with $100 \mu \mathrm{l}$ of pure goat anti-C1q antibody diluted 1:400 in $0.01 \mathrm{M}$ carbonate buffer $\mathrm{pH} 7.6$ and incubated overnight at $4^{\circ} \mathrm{C}$. Plates were washed and $200 \mu 1$ of $2 \%$ bovine serum albumin (BSA) in $0.01 \mathrm{M}$ PBS pH 7.4 was added to all wells in order to saturate the non-coated sites. After repeated washing $100 \mu \mathrm{l}$ of patients' serum, calibrators and controls, at a dilution of $1: 100$ in $0.01 \mathrm{M}$ PBS pH 7.4 containing $2 \%$ BSA and $0.05 \%$ Tween 20 were added to different duplicate wells and incubated for one hour at room temperature. Several wells containing all reagents, but not serum, were used for measurement of the reaction background or blank. During this incubation, sera containing C1q-immune complexes bind 
strongly to anti-C1q-coated microwells. Following washing and removal of unbound serum proteins, alkaline phosphatase labeled anti-human IgA was added to different sets of microwell plates, which were then incubated again for one hour. The secondary IgA antibody specifically will bind to IgA immune complexes that are bound to the microwell coated with anti-Clq antibody. After a repeat of the washing step, addition of substrate para-nitrophenylphosphate concentration of $1 \mu \mathrm{g} / \mathrm{ml}$, and incubation for 30 minutes at room temperature, a yellow color is developed in proportion to the concentration of CIC in the samples. Then $60 \mu \mathrm{l}$ of $2 \mathrm{~N} \mathrm{NaOH}$ is added to stop the reaction and produce the endpoint color, which is measured by an ELISA reader at $405 \mathrm{~nm}$. The indices of circulating immune complexes (CIC) in the samples are calculated using data from sera with known concentration of CIC put in the following formula: immune complex index = OD sample - OD blank / OD calibrator - OD blank.

As explained previously [28], ELISA was used to measure claudin-5, occludin, Ecadherin, talin, vinculin, epithelial intermediate filament (EIF), PLVAP, and epithelial and endothelial adherent junctions (ß-catenin) (Bio-Synthesis Inc., Lewisville, TX USA; and Abcam, Cambridge, MA USA) and actin (Sigma-Aldrich, St Louis, MO USA) [28]. We used the PARA+VASC/TRANS score [28] as an index of breakdown of paracellular and vascular pathway, computed as z (z score of IgA to occludin (z Occludin) + z Claudin $-5+z$ E-cadherin + $\mathrm{z} \beta$-catenin $+\mathrm{z}$ PLVAP $)-\mathrm{z}$ score $(\mathrm{z}$ talin $+\mathrm{z}$ actin $+\mathrm{z}$ vinculin $+\mathrm{z}$ EIF). As explained previously, IgA and IgM isotypes directed to the LPS of Hafnia alvei, Klebsiella pneumonia, Morganella morganii, Pseudomonas aeruginosa, and Pseudomonas putida were assayed using ELISA methods [37]. Consequently, we computed the sum of all 5 IgA and all 5 IgM responses to those bacteria as indicants of bacteria load (BACT-LOAD). In addition, we computed a new composite score reflecting breakdown of the paracellular and vascular pathways and bacterial load (PARA+VASC+BACT) as $\mathrm{z}$ E-Cadherin $+\mathrm{z}$ PLVAP $+\mathrm{z}$ Catenin $+\mathrm{z}$ BACT-LOAD. Indirect EISA tests were employed to assay IgM levels directed against conjugated MDA, azelaic acid, oleic acid, and phosphatidylinositol (Pi) as explained previously [1,27]. Consequently, we used the first principal component (PC) extracted from the 4 optical density values reflecting the IgM protectome [1,27]. As explained previously in the above-mentioned reports no significant effects of the drug state of the patients were found on these measurements. In the current we found that there were no significant effects of the drug state on the newly composed composite scores and $\mathrm{IgA}$ to $\mathrm{Clq}$.

\section{Statistics}

Analysis of variance (ANOVA) was employed to assess the differences in scale or ordinal variables between groups and analysis of contingency tables ( $\mathrm{X}^{2}$-test) to assess associations between two sets of categorical variables. In order to correct for type 1 errors due to multiple comparisons we have used p correction for false discovery rate (FDR) [38]. Multinomial and binary logistic regression analysis (automatic step up) was used to delineate the most important variables predicting FES versus MES and controls. The Odd's ratio with 95\% confidence intervals were computed. Nagelkerke pseudo- $\mathrm{R}^{2}$ values were used as estimates of the effect size. Multivariate and univariate general linear model (GLM) analysis was used to delineate the association between diagnostic groups (i.e., deficit versus nondeficit schizophrenia) and biomarkers after considering the effects of MES and FES. Pairwise LSD tests were used to examine multiple comparisons among treatment means. Multiple regression analysis was used to delineate the most important predictors of the BCPS-worsening score. $\mathrm{R}^{2}$ values were used as estimates of the effect size. Principal component analysis was used to extract PCs from a data set 
and a relevant latent vector (LV) was considered when the explained variance was $>50.0 \%$ and when all variable loaded highly on this PC $(>0.66)$. The adequacy for factorization was checked with the Kaiser-Meyer-Olkin (KMO) test and Bartlett's test of sphericity. We used two-step cluster analysis to detect natural groups of subjects not otherwise apparent. This method allows to cluster categorical as well as continuous variables. Here we use log-likelihood as distance measure and Schwarz's Bayesian Criterion as clustering criterion. The cluster solution is accepted only when the silhouette coefficient (measure of cohesion and separation) is adequate (namely $>0.5$ ) indicating validity of the within and between-cluster distances. Statistical analyses were performed using IBM SPSS Windows version 25. Tests were 2-tailed, and an alpha level of 0.05 indicated a statistically significant effect.

\section{Results.}

Socio-demographic and clinical data

Table 1 shows the demographic and clinical data in controls, and FES and MES patients. There were no significant differences in age, marital status, BMI, and TUD between these three groups. There were more males in the schizophrenia groups than in controls. Years of education was significantly lower in FES than in controls. Employment was significantly lower in schizophrenia than in controls. There were no significant differences in age of first diagnosis, duration of illness, a positive family history of psychosis, and the frequency of past suicidal ideation between FES and MES. The number of hospitalizations was significantly higher in MES than in FES patients.

We extracted the first LV from the G-CoDe, OSOS, and OD-QoL scores, which explained $72.84 \%$ of the variance in the data (Kaiser-Meyer-Olkin=0.783). All 4 variables scored highly $(>0.66)$ on this first factor, namely G-CoDe: -0.845 , OSOS 0.872 , and OD-QoL -0.844 . As such, this PC reflects the severity of behavioral-cognitive-physical-psychosocial (BCPS)worsening. We found that the BCPS-worsening, G-CoDe, and OSOS scores were significantly different between schizophrenia patients and controls. There were no significant differences in BCPS-worsening and G-CoDe scores between MES and FES. The OD-Qol scores were significantly different between the three study groups and decreased from controls $\rightarrow$ FES $\rightarrow$ MES. The ratio of deficit versus non-deficit schizophrenia was not significantly different between FES and MES.

\section{Biomarkers in FES versus MES and controls.}

In order to delineate the biomarker differences between FES, MES, and controls we performed multinomial logistic regression analysis to delineate the best predictors of FES and MES using PARA+VASC/TRANS, immune activation, IgM protectome, C1q, sum IgA and sum IgM to Gram-negative bacteria, 3OX, 3ANTIOX, and zPA+XA+3HK as explanatory variables. The immune activation, IgM protectome, and 3OX scores did not differ between FES and MES and the other biomarkers did not differ between MES and controls. Therefore, we have performed binary logistic regression analysis with FES as dependent variable and no-FES (controls and MES) as reference group (using the oversampling method). Table 2 shows that PARA+VASC/TRANS, IgA to $\mathrm{Clq}$, IgM/IgA to Gram-negative bacteria, 3ANTIOX, and zPA $+\mathrm{XA}+3 \mathrm{HK}$ significantly predicted FES versus MES and controls. These differences remained significant (all at $\mathrm{p}<0.027$ ) after $\mathrm{p}$-correction for $\mathrm{FDR}$, except $\mathrm{zAA}+\mathrm{XA}+3 \mathrm{HK}$ $(\mathrm{p}=0.062)$. Consequently, we analyzed the components of the PARA+VASC/TRANS, IgM/IgA 
to Gram-negative bacteria, and 3ANTIOX scores, and detected that FES is accompanied by increased IgA to cadherin, PLVAP, catenin, Clq CIC, H. Alvei, P. putida, K. pneumonia, IgM to 4 Gram-negative bacteria, and their composite scores BACT-LOAD and PARA+VASC+BACT. These predictions remained significant after FDR p-correction performed on the components of the composite scores. FES was best predicted by a combination of TRAP, IgA to C1q, and the PARA+VASC+BACT composite score. Figure 1 shows a clustered bar graph with the z values of the leaky gut biomarkers, IgA to $\mathrm{Clq}$, and zPA+XA+3HK (higher in FES) and the 3ANTIOX and TRAP z scores (lower in FES).

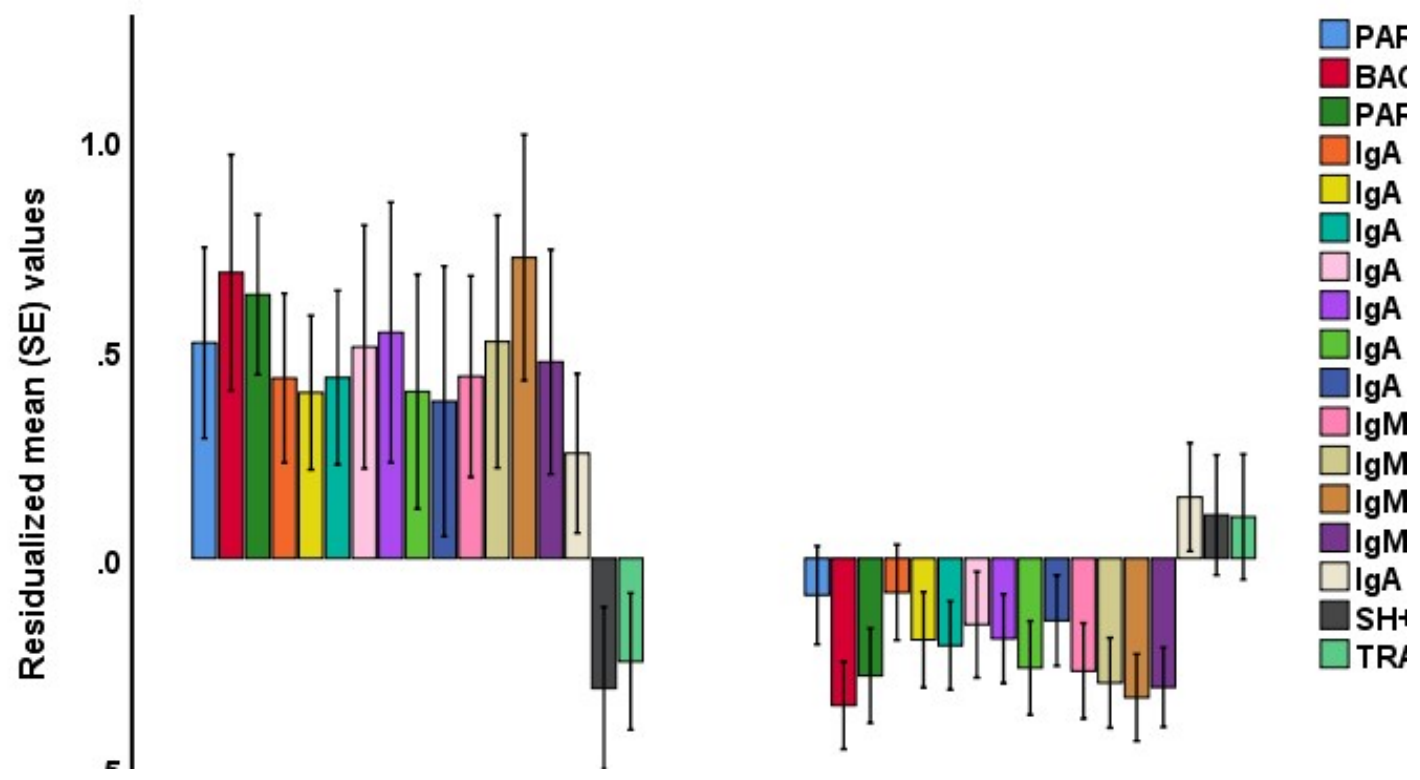

Figure 1. Clustered bar graph showing the mean z scores (SE) of different biomarkers in first (FES) and multiple episode (MES) schizophrenia. PARA+VASC/TRANS: index of breakdown of paracellular and vascular pathways; BACT-LOAD: computed as sum of IgA and IgM responses to Gram-negative bacteria; PARA+VASC+BACT: indicant of breakdown of paracellular and vascular barriers and bacterial translocation; PLVAP: plasmalemma vesicle associated protein; $P A+X A+3 H K$ : indicant of increased tryptophan catabolite pathway activity; PA: picolinic acid, XA: xanthurenic acid, 3HK: 3-hydroxy kynurenine; SH+PON1+TRAP: indicant of lowered antioxidant capacity; SH: sulfhydryl groups, PON: paraoxonase 1 activity; TRAP: total radical-trapping antioxidant parameter.

\section{Results of cluster analysis}

In order to detect whether relevant classes other than MES and FES may be detected in the data set, we performed a two-step cluster analysis with FES, MES, and controls as categorical variables and G-CoDe, OSOS, and OD-QoL as continuous variables. Four clusters were formed, namely controls and FES, and two MES subgroups, a first with 27 (MES type1) and a second with 31 (MES type2) patients. The silhouette measure of cohesion and separation $(>0.5)$ indicated that the model was adequate. Table 3 shows that there were no significant differences in socio-demographic data between both MES subgroups, except education which was somewhat lower in MES type2. The number of hospitalizations was significantly higher in MES type2 than MES type1.

Table 4 shows the various worsening indices in controls, FES, MES type1, and MES type2. The BCPS-worsening and OSOS scores were significantly different between the 4 groups 
and increased from controls $\rightarrow$ MES type1 $\rightarrow$ FES $\rightarrow$ MES type2. The G-CoDe and OD-QoL scores were significantly higher in controls versus all patients and significantly lower in MES type 2 as compared with all other subjects. Table 5 shows the significant association between the FES/MES classes and deficit schizophrenia $(\chi 2=25.25, \mathrm{df}=2, \mathrm{p}<0.001)$. The frequency of deficit schizophrenia was significantly higher in FES and MES type 2 than in MES type1, whereas there were no differences between FES and MES type2.

\section{Biomarkers in MES type 1 versus MES type 2}

Table 4 shows the differences in biomarkers between MES type 1 and MES type 2 and FES and controls. First, we have examined differences PARA+VASC/TRANS, IgA to C1q, immune activation, zPA $+\mathrm{XA}+3 \mathrm{HK}, 3 \mathrm{OX}, 3 \mathrm{ANTIOX}$, and IgM protectome between the groups and detected significant intergroup differences in all those biomarkers (all at $p<0.029$ ), except IgA to $\mathrm{Clq}(\mathrm{p}=0.089)$. Consequently, we have also examined differences in the components of the composite scores as shown in table 4. The PARA+VASC/TRANS ratio was significantly higher in FES as compared with controls and MES type1 and higher in MES type 2 than in MES type1. The BACT-LOAD and PARA+VASC+BACT scores and IgA to C1q were significantly higher in FES than in all other groups. The immune activation index was significantly higher in all patient groups than in controls and higher in MES type 2 than in all other patient groups. The neurotoxicity index was significantly higher in MES type 2 than in all other study samples and higher in FES than in controls and MES type1. IL-6 and MIP were significantly higher in MES type 2 than in controls. TNF- $\alpha$ was significantly higher in MES type 2 than in all other study groups. CCL11 was significantly higher in the patient groups as compared with controls. IL-10 was significantly higher in all patient groups than in controls and higher in MES type2 than in FES and MES type1. The composite TRYCAT score was significantly higher in MES type 2 and FES than in controls. 3OX was higher in MES type2 than in controls and MES type1. 3ANTIOX was significantly lower in FES and MES type2 than in MES type1. 3OX-3ANTIOX was significantly higher in MES type2 than in controls and MES type1 and higher in FES than in MES type1. PON1 activity was significantly lower in MES type 2 than in controls and MES type1. The IgM protectome was significantly lower in MES type 2 than in all other study groups.

\section{Prediction of the BCPS-worsening score}

Table 6 shows the results of multiple regression analyses with the BCPS-worsening score as dependent variable and the biomarkers, number of episodes, and MES versus FES, and age, sex, BMI, and education as explanatory variables. Regression \#1 shows that, in the total study group, $38.5 \%$ of the variance in the BCPS-worsening score could be explained by TNF- $\alpha$, $\mathrm{zPA}+\mathrm{XA}+3 \mathrm{HK}, \mathrm{CCL} 11$, and 3OX (all positively associated). In patients with schizophrenia (regression \#2a), 29.1\% of the variance in the BCPS-worsening score could be explained by the regression on IgA to $K$. pneumoniae, 3OX-3ANTIOX, and MES (all positively). Entering number of episodes instead of MES (regression \#2b) showed a somewhat better model with $34.0 \%$ of the variance being explained.

In FES, $48.7 \%$ of the variance in the BCPS-worsening score could be explained by IgA

to $K$. pneumoniae (positively) and PON1 activity (inversely) (regression \#3). Moreover, correlation analysis showed significant associations between BCPS-worsening and BACTLOAD $(r=0.443, p=0.044)$ and 3 ANTIOX $(r=-0.468, p=0.033)$. Regression \#4 shows that IgA to $K$. pneumoniae was the single best predictor of psychosis in FES explaining $44.1 \%$ of the variance. In MES (regression \#5), we found that $42.7 \%$ of the variance in the BCPS-worsening 
score was explained by the regression on 3OX-3ANTIOX, TNF- $\alpha$, and number of episodes (all positively). Moreover, correlation analysis showed significant associations between BCPSworsening and immune activation $(\mathrm{r}=0.589, \mathrm{p}<0.001)$, neurotoxicity $(\mathrm{r}=0.434, \mathrm{p}=0.001), 3 \mathrm{OX}$ $(\mathrm{r}=0.336, \mathrm{p}=0.010), 3 \mathrm{ANTIOX}(\mathrm{r}=-0.362, \mathrm{p}=0.006)$, and $\operatorname{IgA}$ to $K$. pneumoniae $(\mathrm{r}=0.356$, $\mathrm{p}=0.006$ ). Regression \#6 shows that IgA to $K$. pneumoniae was the single best predictor of psychosis in MES explaining $10.1 \%$ of the variance.

We have also examined the correlations between IgA to C1q and signs of leaky gut and bacterial translocation. In schizophrenia we observed significant correlations between IgA to C1q and BACT-LOAD ( $\mathrm{r}=0.361, \mathrm{p}=0.001)$, IgM to K. pneumoniae ( $\mathrm{r}=0.348, \mathrm{p}=0.002)$, P. putida $(\mathrm{r}=0.394, \mathrm{p}<0.001)$, M. morganii $(\mathrm{r}=0.388, \mathrm{p}<0.001), P$. aeruginosa $(\mathrm{r}=0.395, \mathrm{p}<0.001)$, PARA+VASC+BACT $(\mathrm{r}=0.431, \mathrm{p}<0.001)$, and IgA to E-cadherin $(\mathrm{r}=0.341, \mathrm{p}=0.002)$, PLVAP $(\mathrm{r}=0.345, \mathrm{p}=0.002)$, and catenin $(\mathrm{r}=0.349, \mathrm{p}=0.002)$.

Associations between the deficit syndrome and biomarkers

In order to examine the differences in the biomarkers between deficit and nondeficit schizophrenia while considering the effects of MES and FES we performed univariate GLM analyses with deficit (versus nondeficit) schizophrenia and MES/FES as fixed categories.

Figure 2 shows the residualized leaky gut values in deficit versus non-deficit schizophrenia after regression on the MES/FES data. The residualized biomarker values of PARA+VASC/TRANS $(\mathrm{F}=31.26, \mathrm{df}=1 / 75, \mathrm{p}<0.001), \mathrm{PARA}+\mathrm{VASC}+\mathrm{BACT}(\mathrm{F}=10.60, \mathrm{df}=1 / 75, \mathrm{p}=0.002)$, BACT-

$\operatorname{LOAD}(\mathrm{F}=5.17, \mathrm{df}=1 / 75, \mathrm{p}=0.026)$, and $\operatorname{IgA}$ to E-cadherin $(\mathrm{F}=8.32, \mathrm{df}=1 / 75, \mathrm{p}=0.005)$, catenin $(\mathrm{F}=11.18, \mathrm{df}=1 / 75, \mathrm{p}=0.001)$, H. alvei $(\mathrm{F}=9.57, \mathrm{df}=1 / 75, \mathrm{p}=0.003)$, and $K$. pneumoniae $(\mathrm{F}=9.99$, $\mathrm{df}=2 / 75, \mathrm{p}=0.002$ ) were significantly higher in deficit than nondeficit schizophrenia. There were no significant differences in IgA to PLVAP, C1Q, and P. putida, and IgM responses to Gramnegative bacteria between both groups.

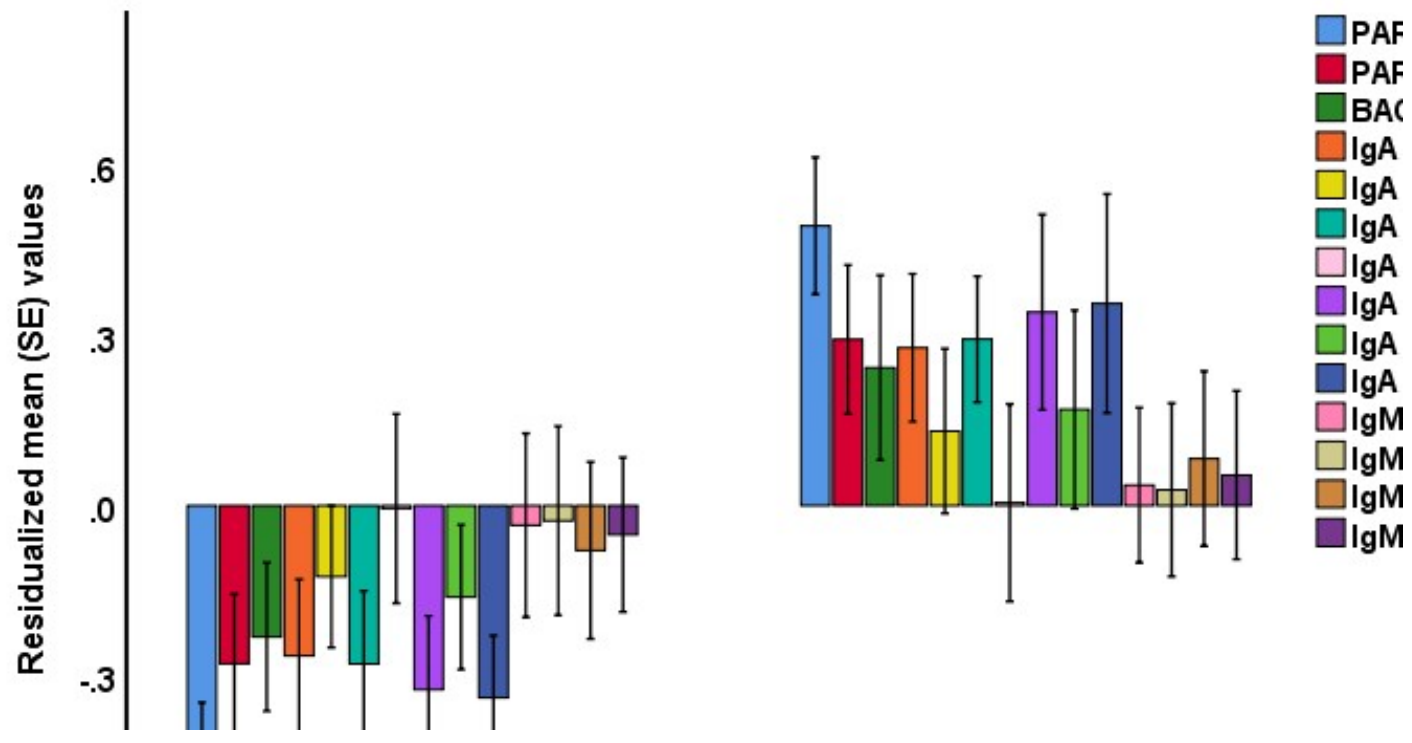

Figure 2. Clustered bar graph showing the mean z scores (SE) of different biomarkers in deficit and nondeficit schizophrenia afte adjusting for the effects of first and multiple episode schizophrenia. PARA+VASC/TRANS: index of breakdown of paracellular and vascular pathways; BACT-LOAD: computed as sum of IgA and IgM responses to Gram-negative bacteria; PARA+VASC+BACT: indicant of breakdown of paracellular and vascular barriers and bacterial translocation; PLVAP: plasmalemma vesicle associated protein. 
Table 1. Sociodemographic and clinical data in healthy controls and stable-phase, and first episode (FES) and multiple episode (MES) schizophrenia.

\begin{tabular}{|c|c|c|c|c|c|c|}
\hline Variables & $\mathrm{HC}^{\mathrm{A}}$ & FES $^{B}$ & MES $^{\mathrm{C}}$ & $F / X^{2}$ & df & $\mathbf{P}$ \\
\hline Age (years) & $37.4(12.8)$ & $38.4(12.0)$ & $41.9(10.7)$ & 2.00 & $2 / 116$ & 0.140 \\
\hline Female/male ratio & $30 / 10$ & $11 / 10$ & $25 / 33$ & 9.85 & 2 & 0.007 \\
\hline Marital status & $23 / 14 / 3$ & $16 / 4 / 1$ & $43 / 7 / 6$ & 7.21 & - & 0.111 \\
\hline $\mathrm{BMI}(\mathrm{kg} / \mathrm{m} 2)$ & $24.0(4.3)$ & $24.9(5.7)$ & $24.4(4.9)$ & 0.25 & $2 / 111$ & 0.780 \\
\hline Education (years) & $14.3(4.9)^{B}$ & $11.4(5.3)^{\mathrm{A}}$ & $12.6(3.7)$ & 3.21 & $2 / 116$ & 0.044 \\
\hline TUD (N/Y) & $38 / 2$ & $20 / 1$ & $54 / 4$ & 0.271 & - & 1.00 \\
\hline Employment (N/Y) & $4 / 36$ & $8 / 13$ & $37 / 21$ & 28.38 & 2 & $<0.001$ \\
\hline Age first diagnosis (years) & & $26.9(12.4)$ & $24.5(8.9)$ & 0.82 & $1 / 73$ & 0.370 \\
\hline Duration since first episode (years) & & $12.2(14.5)$ & $17.4(10.5)$ & 2.91 & $1 / 73$ & 0.092 \\
\hline Number psychoses & & 1 & $4.2(2.8)$ & & & \\
\hline Familial history psychosis (N/Y) & & $14 / 7$ & $33 / 25$ & 0.61 & 1 & 0.435 \\
\hline Suicidal ideation past & & $0.85(2.33)$ & $1.24(2.22)$ & 0.33 & $1 / 72$ & 0.570 \\
\hline Number hospitalizations & & $0.30(0.58)^{c}$ & $2.12(2.33)^{B}$ & 11.92 & $1 / 76$ & 0.001 \\
\hline BCPS-worsening score & $-0.973(0.420)^{B, C}$ & $0.301(0.894)^{A}$ & $0.563(0.815)^{A}$ & 55.53 & $2 / 116$ & $<0.001$ \\
\hline G-CoDe score & $0.797(0.741)^{\mathrm{B}, \mathrm{C}}$ & $-0.260(0.865)^{A}$ & $-0.461(0.872)^{\mathrm{A}}$ & 28.46 & $2 / 116$ & $<0.001$ \\
\hline OSOS score & $-0.902(0.032)^{B, C}$ & $0.462(0.916)^{A}$ & $0.452(0.967)^{A}$ & 40.45 & $2 / 116$ & $<0.001$ \\
\hline OD-Qol score & $0.793(0.598)^{B, C}$ & $-0.048(0.937)^{A, C}$ & $-0.530(0.898)^{A, B}$ & 31.02 & $2 / 116$ & $<0.001$ \\
\hline Nondeficit/deficit schizophrenia & & $9 / 12$ & $31 / 27$ & 0.69 & 1 & 0.406 \\
\hline
\end{tabular}

Results are shown as mean (SD). All results of ANOVAs or $\chi^{2}$ tests. ${ }^{A, B, C}$ : results of pairwise comparisons among groups means or frequencies

Marital status: ratio of married / single / widowed; BMI: body mass index; TUD: tobacco use disorder; BCPS: behavioral-cognitive-physicalpsychosocial; G-CoDe: generalized cognitive decline; OSOS: overall severity of symptoms; OD-Qol: overall decline in health-related quality of life (WHO-QoL-BREF scale) 
Table 2. Results of binary logistic regression analysis with stable phase first episode schizophrenia as dependent variable and biomarkers as explanatory variables.

\begin{tabular}{|l|l|l|l|l|l|l|l|}
\hline $\begin{array}{l}\text { Explanatory variables (entered as z } \\
\text { scores) }\end{array}$ & B & SE & Wald & $\mathbf{p}$ & OR & lower & Upper \\
\hline PARA+VASC/TRANS & 0.608 & 0.160 & 14.53 & $<0.001$ & 1.84 & 1.34 & 2.51 \\
\hline BACT-LOAD & 0.750 & 0.170 & 19.52 & $<0.001$ & 2.12 & 1.52 & 2.95 \\
\hline PARA+VASC+BACT & 0.847 & 0.181 & 21.93 & $<0.001$ & 2.33 & 1.64 & 3.32 \\
\hline IgA Cadherin & 0.480 & 0.156 & 9.47 & 0.002 & 1.92 & 1.19 & 2.20 \\
\hline IgA PLVAP & 0.539 & 0.171 & 9.88 & 0.002 & 1.71 & 1.23 & 2.40 \\
\hline IgA Catenin & 0.555 & 0.165 & 11.35 & 0.001 & 1.74 & 1.26 & 2.41 \\
\hline IgA C1q & 0.495 & 0.150 & 10.91 & 0.001 & 1.61 & 1.22 & 2.20 \\
\hline IgA 5 Gram-negative bacteria & 0.355 & 0.146 & 5.95 & 0.015 & 1.43 & 1.07 & 1.90 \\
\hline IgA H alvei & 0.626 & 0.181 & 11.97 & 0.001 & 1.87 & 1.21 & 2.67 \\
\hline IgA P putida & 0.939 & 0.143 & 7.54 & 0.006 & 1.48 & 1.12 & 0.96 \\
\hline IgA K pneumoniae & 0.391 & 0.150 & 6.80 & 0.009 & 1.48 & 1.10 & 1.98 \\
\hline IgM 5 Gram-negative bacteria & 0.562 & 0.162 & 12.07 & 0.001 & 1.75 & 1.28 & 2.41 \\
\hline IgM Paeruginosa & 0.513 & 0.158 & 10.61 & 0.001 & 1.67 & 1.23 & 2.28 \\
\hline IgM M morganii & 0.511 & 0.148 & 11.87 & 0.001 & 1.67 & 1.25 & 2.23 \\
\hline IgM P putida & 0.815 & 0.182 & 20.06 & $<0.001$ & 2.26 & 1.25 & 3.23 \\
\hline IgM K pneumoniae & 0.488 & 0.156 & 9.79 & 0.002 & 1.63 & 1.20 & 2.21 \\
\hline IgA PA+XA+3HK & 0.120 & 0.058 & 4.19 & 0.041 & 1.13 & 1.01 & 1.26 \\
\hline zSH+PON1+TRAP & -0.455 & 0.161 & 7.65 & 0.006 & 0.64 & 0.47 & 0.88 \\
\hline TRAP & -0.426 & 0.178 & 5.70 & 0.017 & 0.65 & 0.46 & 0.93 \\
IgA C1q & 0.319 & 0.161 & 3.94 & 0.047 & 1.38 & 1.00 \\
PARA+VASC+BACT & 0.737 & 0.192 & 14.81 & $<0.001$ & 2.09 & 1.44 & 1.88 \\
\hline PARA+VASC/TRAS: & 3.04 &
\end{tabular}

PARA+VASC/TRANS: index of breakdown of paracellular and vascular pathways; BACT-LOAD: computed as sum of IgA and IgM responses to Gram-negative bacteria; PARA+VASC+BACT: indicant of breakdown of paracellular and vascular barriers and bacterial translocation; PLVAP: plasmalemma vesicle associated protein; ZPA+XA+3HK: indicant of increased tryptophan catabolite pathway activity; XA: xanthurenic acid, PA: picolinic acid, 3HK: 3-hydroxy kynurenine; SH+PON1+TRAP: indicant of lowered antioxidant capacity; SH: sulfhydryl groups, PON: paraoxonase 1 activity; TRAP: total radical-trapping antioxidant parameter. 
Table 3. Socio-demographic and clinical differences between two cluster-analytically generated clusters of multiple episodes (MES) schizophrenia.

\begin{tabular}{|c|c|c|c|c|c|}
\hline Variables & MES type1 (n=25) & MES type2 $(n=31)$ & $F / \chi^{2}$ & df & $\mathbf{P}$ \\
\hline $\operatorname{Sex}(F / M)$ & $12 / 13$ & $12 / 19$ & 0.49 & 1 & 0.485 \\
\hline $\mathrm{BMI}\left(\mathrm{kg} / \mathrm{m}^{2}\right)$ & $25.7(5.3)$ & $23.6(4.5)$ & 2.55 & $1 / 51$ & 0.117 \\
\hline Education (years) & $13.8(3.8)$ & $11.8(3.4)$ & 4.17 & $1 / 54$ & 0.046 \\
\hline TUD (N/Y) & $23 / 2$ & $29 / 2$ & FEPT & - & 1.000 \\
\hline Number psychoses & $3.5(2.0)$ & $4.5(3.2)$ & 1.82 & $1 / 50$ & 0.183 \\
\hline Duration since first episode (years) & $15.6(9.6)$ & $18.7(11.2)$ & 1.11 & $1 / 52$ & 0.298 \\
\hline Familial History of psychosis (N/Y) & $12 / 13$ & $20 / 11$ & 1.54 & 1 & 0.214 \\
\hline Frequency of suicidal ideation, past & $0.74(1.29)$ & $1.67(2.73)$ & 2.26 & $1 / 51$ & 0.139 \\
\hline Number of hospitalizations & $1.32(1.38)$ & $2.48(2.45)$ & 4.50 & $1 / 54$ & 0.039 \\
\hline
\end{tabular}

Results are shown as mean (SD). FETP: Fisher's exact probability test.

Marital status: ratio of married / single / widowed; BMI: body mass index; TUD: tobacco use disorder 
Table 4. Differences in worsening indices and biomarkers between healthy controls (HC), patients with first episode (FES) and multiple episode (MES) schizophrenia subdivided into MES type1 and MES type2.

\begin{tabular}{|c|c|c|c|c|c|c|c|}
\hline $\begin{array}{l}\text { Variables (all in z } \\
\text { scores) }\end{array}$ & $H C(n=40)^{A}$ & FES $(n=21)^{B}$ & MES type1 $(n=25)^{c}$ & MES type2 $(n=31)^{D}$ & $\mathbf{F}$ & df & $\mathbf{P}$ \\
\hline BCPS-worsening score & $-0.973(0.420)^{B, C, D}$ & $0.301(0.895)^{A, C, D}$ & $-0.104(0.545)^{A, B, D}$ & $1.064(0.606)^{A, B, C}$ & 68.94 & $3 / 113$ & $<0.001$ \\
\hline G-CoDe & $0.797(0.741)^{B, C, D}$ & $-0.260(0.865)^{A, D}$ & $0.076(0.555)^{\mathrm{A}, \mathrm{D}}$ & $-0.924(0.850)^{A, B, C}$ & 30.73 & $3 / 113$ & $<0.001$ \\
\hline OSOS & $-0.902(0.032)^{B, C, D}$ & $0.462(0.916)^{A, C, D}$ & $-0.306(0.551)^{A, B, D}$ & $0.940(1.004)^{A, B, C}$ & 61.18 & $3 / 113$ & $<0.001$ \\
\hline OD-QoL & $0.793(0.598)^{B, C, D}$ & $-0.048(0.937)^{A, D}$ & $-0.115(0.926)^{A, D}$ & $-0.860(0.743) \mathrm{A}, \mathrm{B}, \mathrm{C}$ & 26.58 & $3 / 113$ & $<0.001$ \\
\hline PARA+VASC/TRANS & $-0.177(1.042)^{\mathrm{B}}$ & $0.515(1.046)^{A, C}$ & $-0.460(0.852)^{\mathrm{B}, \mathrm{C}}$ & $0.207(0.856)^{A, C}$ & 4.89 & $3 / 113$ & 0.003 \\
\hline BACT-LOAD & $0.103(0.853)^{\mathrm{B}, \mathrm{C}}$ & $0.683(1.294)^{A, C, D}$ & $-0.420(0.776)^{A, B}$ & $-0.252(0.822)^{\mathrm{B}}$ & 6.47 & $3 / 113$ & $<0.001$ \\
\hline PARA+VASC+BACT & $0.036(1.083)^{\mathrm{B}}$ & $0.631(0.879)^{A, C, D}$ & $-0.364(0.881)^{\mathrm{B}}$ & $-0.181(0.872)^{\mathrm{B}}$ & 4.68 & $3 / 113$ & 0.004 \\
\hline IgA to C1q & $-0.031(0.774)^{B}$ & $0.506(1.334)^{A, C, D}$ & $-0.089(1.117)^{\mathrm{B}}$ & $-0.179(0.865)^{\mathrm{B}}$ & 2.23 & $3 / 113$ & 0.089 \\
\hline Immune activation & $-0.736(0.756)^{B, C, D}$ & $0.184(0.819)^{A, D}$ & $-0.017(0.714)^{A, D}$ & $0.802(0.928)^{A, B, C}$ & 21.63 & $3 / 113$ & $<0.001$ \\
\hline Neurotoxicity & $-0.509(0.834)^{\mathrm{B}, \mathrm{D}}$ & $0.069(0.821)^{A, D}$ & $-0.175(0.887)^{\mathrm{D}}$ & $0.698(0.987)^{A, B, C}$ & 11.16 & $3 / 113$ & $<0.001$ \\
\hline Interleukin-6 (IL-6) & $-0.325(0.724)^{D}$ & $0.052(0.941)$ & $0.201(1.384)$ & $0.247(0.943)^{\mathrm{A}}$ & 2.44 & $3 / 113$ & 0.068 \\
\hline TNF- $\alpha$ & $-0.267(0.647)^{D}$ & $-0.106(1.013)^{D}$ & $-0.359(0.693)^{\mathrm{D}}$ & $0.671(1.254)^{A, B, C}$ & 7.98 & $3 / 113$ & $<0.001$ \\
\hline CCL11 (eotaxin) & $-0.685(0.907)^{B, C, D}$ & $0.213(0.661)^{\mathrm{A}}$ & $0.459(0.706)^{\mathrm{A}}$ & $0.376(1.086)^{\mathrm{A}}$ & 12.55 & $3 / 113$ & $<0.001$ \\
\hline slL-1 receptor antagonist & $-0.470(0.837)^{C, D}$ & $0.166(1.086)$ & $0.532(1.099)^{\mathrm{A}}$ & $0.181(0.922)^{\mathrm{A}}$ & 6.29 & $3 / 113$ & 0.001 \\
\hline IL-10 & $-0.721(0.683)^{B, C, D}$ & $0.336(0.782)^{A, D}$ & $0.064(0.814)^{A, D}$ & $0.672(1.078)^{A, B, C}$ & 17.29 & $3 / 113$ & $<0.001$ \\
\hline $\begin{array}{l}\text { Macrophage } \\
\text { inflammatory protein }\end{array}$ & $-0.296(0.849)^{D}$ & $0.168(1.012)$ & $-0.045(1.096)$ & $0.313(1.017)^{\mathrm{A}}$ & 2.50 & $3 / 113$ & 0.063 \\
\hline $\mathrm{ZXA}+\mathrm{PA}+3 \mathrm{HK}$ & $-0.353(1.021)^{\mathrm{B}, \mathrm{D}}$ & $0.251(0.873)^{A}$ & $-0.101(0.909)$ & $0.344(1.041)^{A}$ & 3.56 & $3 / 113$ & 0.017 \\
\hline $\mathrm{zLOOH+MDA+AOPP}$ & $-0.357(0.873)^{D}$ & $-0.036(0.873)$ & $-0.155(0.718)^{D}$ & $0.492(1.204)^{A, C}$ & 4.81 & $3 / 110$ & 0.003 \\
\hline ZSH+PON1+TRAP & $0.025(0.902)$ & $-0.310(0.892)^{C}$ & $0.504(1.051)^{\mathrm{B}, \mathrm{D}}$ & $-0.173(1.071)^{c}$ & 3.23 & $2 / 113$ & 0.025 \\
\hline 3OX-3ANTIOX & $-0.287(1.040)^{\mathrm{B}, \mathrm{D}}$ & $0.237(0.846)^{A, C}$ & $-0.418(0.985)^{\mathrm{B}, \mathrm{D}}$ & $0.440(0.838)^{A, C}$ & 5.45 & $3 / 110$ & 0.002 \\
\hline TRAP & $-0.013(0.900)$ & $-0.246(0.749)^{c}$ & $0.437(1.104)^{\mathrm{B}}$ & $-0.116(1.144)$ & 2.19 & $3 / 113$ & 0.094 \\
\hline PON1 & $0.301(0.976)^{D}$ & $-0.155(1.130)$ & $0.263(0.873)^{\mathrm{D}}$ & $-0.475(0.898)^{A, C}$ & 4.60 & $3 / 113$ & 0.004 \\
\hline IgM protectome & $0.263(0.836)^{D}$ & $0.168(0.963)^{D}$ & $0.138(1.012)^{\mathrm{D}}$ & $-0.446(1.007)^{A, B, C}$ & 3.74 & $3 / 113$ & 0.013 \\
\hline
\end{tabular}

$A, B, C, D$ : results of pairwise comparisons among groups means or frequencies

BCPS: behavioral-cognitive-physical-psychosocial; G-CoDe: generalized cognitive decline; OSOS: overall severity of symptoms; OD-Qol: overall decline in quality of life; PARA+VASC/TRANS: index of breakdown of paracellular and vascular barriers; BACT-LOAD: index of increased bacterial translocation; PARA+VASC+BACT: index of breakdown of paracellular and vascular barriers and increased bacterial translocation; TNF: tumor 
necrosis factor; zPA+XA+3HK: composite score using picolinic acid (PA) + xanthurenic acid (XA) + 3-hydroxykynurenin (3HK); LOOH: lipid hydroperoxides; MDA: malondialdehyde; AOPP: advanced oxidation protein products; -SH: thiol groups; PON1: paraoxonase 1; TRAP: total radical-trapping antioxidant parameter; 3OX-3ANTIOX: ratio of damage due to oxidative stress / antioxidant defenses.

Table 5. Association between the classifications of schizophrenia patients in first episode

(FES) and multiple episode (MES) schizophrenia, type1 and type2, and deficit versus nondeficit schizophrenia.

\begin{tabular}{|l|l|l|l|}
\hline Classes & FES $^{\text {A }}$ & MES type $^{\text {B }}$ & MES type2 $^{\text {C }}$ \\
\hline Nondeficit & 9 & $23^{\text {A,C }}$ & 8 \\
\hline Deficit & $12^{\text {B }}$ & 2 & $23^{B}$ \\
\hline
\end{tabular}

$A, B, C$ : results of pairwise comparisons among groups means or frequencies 
Table 6. Results of multiple regression analysis with the behavioral-cognitive-physical-psychosocial (BCPS)-worsening score as dependent variables and biomarkers as explanatory variables.

\begin{tabular}{|c|c|c|c|c|c|c|c|c|}
\hline $\begin{array}{l}\text { Dependent } \\
\text { Variables }\end{array}$ & Explanatory variables & B & $\mathbf{t}$ & $\mathbf{p}$ & $\mathbf{R 2}$ & Model F & df & $\mathbf{P}$ \\
\hline $\begin{array}{l}\# 1 . \text { BCPS-worsening } \\
\text { score in all subjects } \\
\text { combined }\end{array}$ & $\begin{array}{l}\text { Model } \\
\text { TNF- } \alpha \\
\text { zPA+XA+3HK } \\
\text { CCL11 } \\
3 \mathrm{OX} \\
\end{array}$ & $\begin{array}{l}0.239 \\
0.171 \\
0.377 \\
0.258\end{array}$ & $\begin{array}{l}3.15 \\
2.21 \\
5.02 \\
3.38\end{array}$ & $\begin{array}{l}0.002 \\
0.029 \\
<0.001 \\
0.001\end{array}$ & 0.385 & 17.55 & $4 / 112$ & $<0.001$ \\
\hline $\begin{array}{l}\# 2 \text { a. BCPS- } \\
\text { worsening score in } \\
\text { schizophrenia }\end{array}$ & $\begin{array}{l}\text { Model } \\
\text { IgA K. pneumoniae } \\
\text { 3OX-3ANTIOX } \\
\text { MES }\end{array}$ & $\begin{array}{l}0.355 \\
0.317 \\
0.207 \\
\end{array}$ & $\begin{array}{l}3.49 \\
3.16 \\
2.09 \\
\end{array}$ & $\begin{array}{l}0.001 \\
0.002 \\
0.041 \\
\end{array}$ & 0.291 & 10.11 & $3 / 74$ & $<0.001$ \\
\hline $\begin{array}{l}\text { \#2b. BCPS- } \\
\text { worsening score in } \\
\text { schizophrenia }\end{array}$ & $\begin{array}{l}\text { Model } \\
\text { IgA K. pneumoniae } \\
\text { 3OX-3ANTIOX } \\
\text { Number of episodes }\end{array}$ & $\begin{array}{l}0.322 \\
0.331 \\
0.299 \\
\end{array}$ & $\begin{array}{l}3.32 \\
3.41 \\
3.16 \\
\end{array}$ & $\begin{array}{l}0.001 \\
0.001 \\
0.002\end{array}$ & 0.340 & 12.69 & $3 / 74$ & $<0.001$ \\
\hline $\begin{array}{l}\# 3 \text {. BCPS-worsening } \\
\text { score in FES }\end{array}$ & $\begin{array}{l}\text { Model } \\
\text { IgA K. pneumoniae } \\
\text { PON1 }\end{array}$ & $\begin{array}{l}0.590 \\
-0.412\end{array}$ & $\begin{array}{l}3.39 \\
-2.36\end{array}$ & $\begin{array}{l}0.003 \\
0.030\end{array}$ & 0.487 & 8.05 & $2 / 17$ & 0.003 \\
\hline \#4. Psychosis in FES & $\begin{array}{l}\text { Model } \\
\text { IgA K. pneumoniae }\end{array}$ & 0.664 & 3.77 & 0.001 & 0.441 & 14.21 & $1 / 18$ & 0.001 \\
\hline $\begin{array}{l}\# 5 \text {. BCPS-worsening } \\
\text { score in MES }\end{array}$ & $\begin{array}{l}\text { Model } \\
\text { 3OX-3ANTIOX } \\
\text { TNF- } \alpha \\
\text { Number of episodes }\end{array}$ & $\begin{array}{l}0.383 \\
0.355 \\
0.306\end{array}$ & $\begin{array}{l}3.60 \\
3.34 \\
2.97\end{array}$ & $\begin{array}{l}0.001 \\
0.002 \\
0.004\end{array}$ & 0.427 & 13.40 & $3 / 54$ & $<0.001$ \\
\hline \#6. Psychosis in MES & $\begin{array}{l}\text { Model } \\
\text { IgA K. pneumoniae }\end{array}$ & 0.332 & 2.55 & 0.014 & 0.104 & 6.50 & $1 / 56$ & 0.014 \\
\hline
\end{tabular}

FES: first episode schizophrenia; MES: multiple episode schizophrenia; TNF: tumor necrosis factor; zPA+XA+3HK: composite score of picolinic acid (PA), xanthurenic acid (XA), and 3-hydroxykynurenin (3HK); 3OX-3ANTIOX: index of oxidative stress damage / antioxidant protection; PON1: paraoxonase 1 activity. 
Figure 3 shows the residualized values of the other biomarkers in deficit versus nondeficit schizophrenia after adjusting for the effects of MES/FES. The IgM protectome values $(\mathrm{F}=21.51, \mathrm{df}=1 / 113, \mathrm{p}<0.001)$, PON1 activity $(\mathrm{F}=6.50, \mathrm{df}=1 / 75, \mathrm{p}=0.013)$, and 3ANTIOX $(\mathrm{F}=13.08, \mathrm{df}=1 / 75, \mathrm{p}=0.001)$ were significantly lower in deficit versus nondeficit schizophrenia. The 3OX $(\mathrm{F}=6.94, \mathrm{df}=1 / 75, \mathrm{p}=0.010), 3 \mathrm{OX} / \mathrm{ANTIOX}$ ratio $(\mathrm{F}=18.75, \mathrm{df}=1 / 75, \mathrm{p}<0.001)$, immune activation index $(\mathrm{F}=13.84, \mathrm{df}=1 / 75, \mathrm{p}<0.001)$, neurotoxicity index $(\mathrm{F}=15.16, \mathrm{df}=1 / 75$, $\mathrm{p}<0.001), \mathrm{TNF}-\alpha(\mathrm{F}=13.95, \mathrm{df}=1 / 75, \mathrm{p}<0.001), \mathrm{zA}+\mathrm{XA}+3 \mathrm{HK}(\mathrm{F}=5.77, \mathrm{df}=1 / 75, \mathrm{p}=0.019)$, but not CCL1 $(\mathrm{F}=0.03, \mathrm{df}=1 / 75, \mathrm{p}=0.856)$, were higher in deficit than in nondeficit schizophrenia.

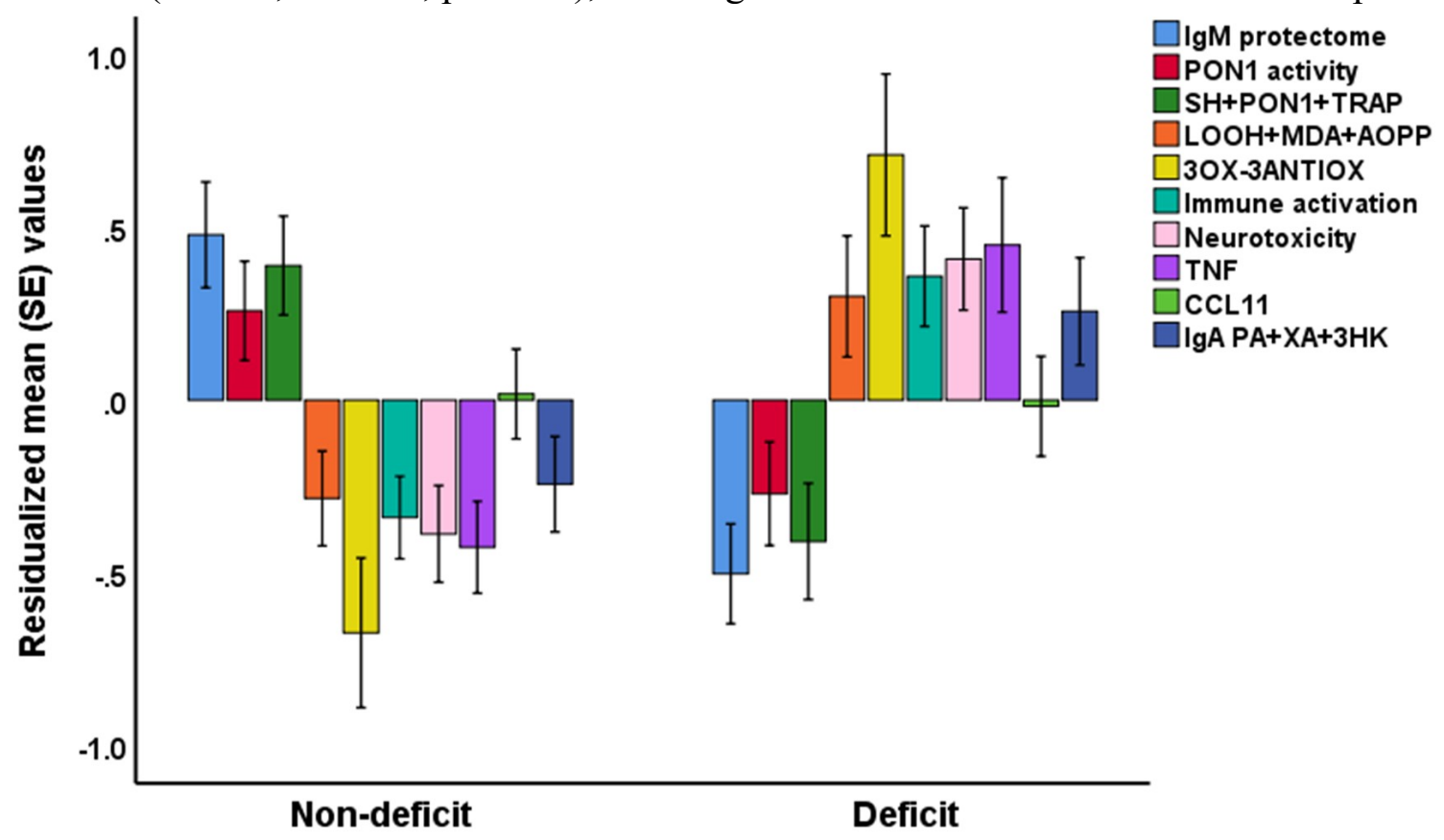

Figure 3. Clustered bar graph showing the mean z scores (SE) of different biomarkers in deficit and nondeficit schizophrenia afte adjusting for the effects of first and multiple episode schizophrenia. PON: paraoxonase; $\mathrm{SH}$ : thiol groups; TRAP: total radical-trapping antioxidant paratmeter; LOOH: lipid hydroperoxides; MDA: malondialdehyde; AOPP: advanced oxidation protein products; 3OX-3ANTIOX: ratio of oxidative stress damage / antioxidant defenses; TNF: tumor necrosis factor; IgA PA+XA+3HK: composite score of picolinic acid (PA) + xanthurenic acid (XA) and 3-hydroxykynurenine (3HK).

Discussion

\section{Clinical aspects of FES and MES}

The first major finding of this study is that the new index indicating BCPS-worsening in schizophrenia was not significantly different between FES and MES, although OD-Qol was significantly lower in MES than in FES. Moreover, based on the G-Code, OSOS, and OD-QoL scores, we discovered two MES subgroups, namely a first with minimal BCPS-worsening and a second with severe BCPS-worsening. Figure 4 summarizes the findings of this study. Interestingly, MES with worsening largely overlaps with the deficit syndrome, while a large part of FES patients already developed a deficit syndrome after a first episode. 


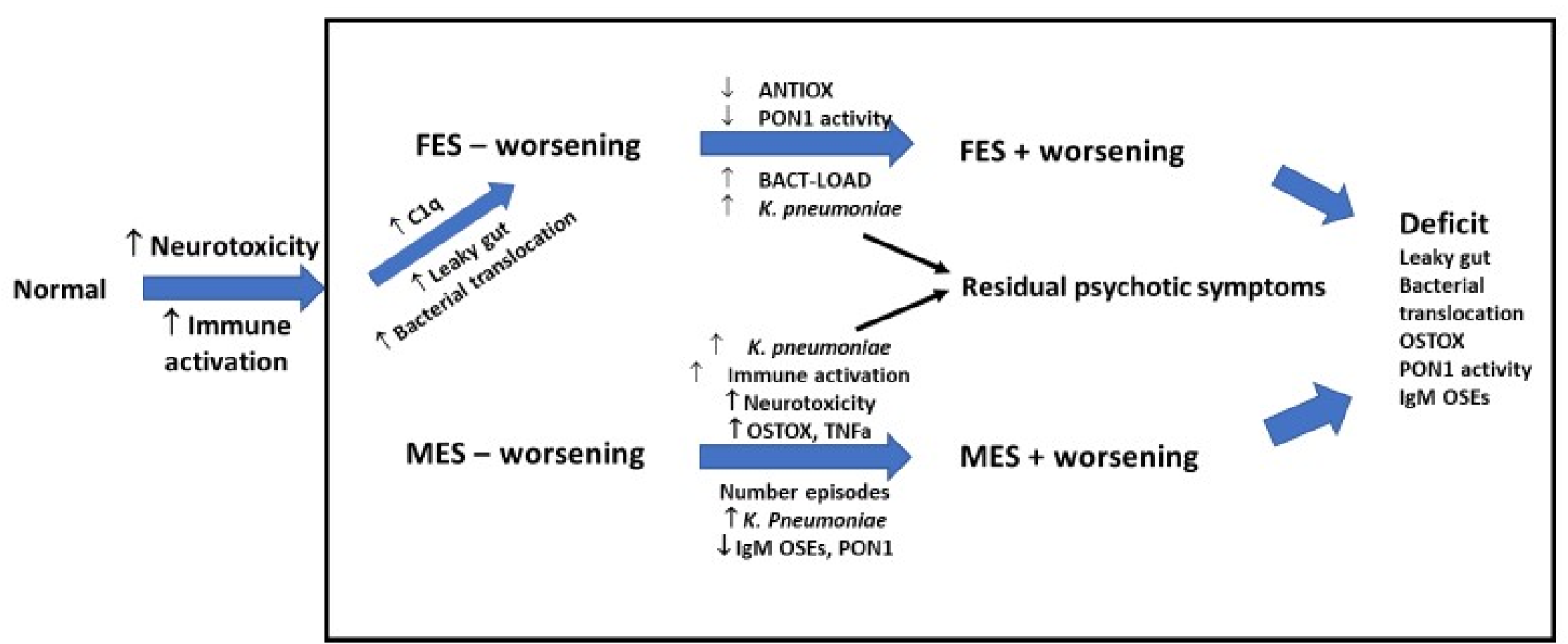

\section{SPECTRUM OF BCPS-WORSENING IN SCHIZOPHRENIA}

Figure 4. Different subtypes of first (FES) and multiple (MES) episode schizophrenia with and without behavioral-cognitive-physical-psychosocial (BCPS) worsening in relation to the deficit syndome and residual psychotic symptoms.

BACT-LOAD: index of bacterial tranlocation and load; PON1: paraoxonase 1; ANTIOX: index of antioxidant capacity; OSTOX: index of oxidative stress toxicity; TNF: tumor necrosis factor; OSE: oxidative specific epitopes. 
Previously, the worsening or deficit was defined as the presence of negative symptoms only [15]. Kanchanatawan et al. [13,14] showed that deficit schizophrenia as defined by negative symptoms is additionally shaped and modeled by PHEM symptoms, PMR, FTD, and neurocognitive deficits. Importantly, the current study constructed a new $\mathrm{z}$ unit-weighted composite score, which reflects symptomatic deterioration including in PHEM and negative symptoms, PMR, and FTD, a cognitive decline in executive functions, semantic and episodic memory, recall, working memory, strategy use, visual sustained attention, attention set-shifting, rule acquisition, and emotional recognition, and self-rated physical and psychological indicators, and a decline in social, and environmentally responsible behaviors. As such, this new BCPSworsening index captures the behavioral-cognitive-physical-psychosocial decline which defines the severity of the worsening in the stable phase.

Around $12-22 \%$ of schizophrenia patients suffer from one acute psychotic episode only [39]. Therefore, our data do not allow to conclude whether our FES patients are in fact suffering from single episode schizophrenia or whether they will develop a relapse and consequently be categorized as MES.

\section{Biomarkers of FES}

The second major finding of this study is that FES is characterized by significantly increased IgA to E-cadherin, catenin, and PLVAP, suggesting damage to the adherens junctions and vascular barriers. E-cadherin and catenin are two key components of adherens junctions whereby catenin stabilizes the junctional complex and its binding to the cytoskeleton [40-42]. PLVAP is an endothelial protein and a major component of the vascular barrier which regulates vascular permeability [42,43]. Previously, we showed increased IgM to zonulin and IgA to occludin in schizophrenia (FES and MES combined), indicating breakdown of the tight junctions of the paracellular pathway [25]. Interestingly, Dzikowski et al. [31] reported that FES is accompanied by increased levels of intestinal biomarkers including antigliadin, transglutaminase 2, and anti-deamidated gliadin peptide antibodies.

Moreover, we found that FES is accompanied by increased IgA and IgM levels directed to diverse gut-commensal bacteria and that $K$. pneumoniae may play a key role in FES, BCPSworsening and residual psychotic symptoms as well. In fact, increased IgA to $K$. pneumoniae was the single best predictor of psychosis in FEP. K. pneumoniae is an opportunistic Gramnegative pathogen in patients under stress [44-46] and it may colonize the gastrointestinal mucosal surfaces and translocate to the blood and grow in many tissues [47]. Microorganisms may target the adherens junctions thereby causing a disruption of the paracellular pathway [48]. These microorganisms use E-cadherin as receptor for adhesion or internalization leading to microbial persistence and increased pathogenesis. For example, P. aeruginosa, one of Gramnegative bacteria assessed in our study, may damage the adherens junctions through changes in the phosphorylation of E-cadherin and p-catenin [49]. Furthermore, Gram-negative bacteria may breach the endothelial barrier by producing toxins or weakening the cytoskeleton [50] and modulate functions of endothelial cells and leukocytes thereby contributing to inflammation and pathogenesis [50].

This study is the first to report that FES is characterized by increased IgA circulating C1q CICs. Previously, we have shown that the acute episode of schizophrenia is accompanied by increased serum levels of $\mathrm{C} 3 \mathrm{C}$ and $\mathrm{C} 4$ [17]. Binding of $\mathrm{C} 1 \mathrm{q}$ to antibody attached to antigen results in activation of the complement classical pathway, which in turn cleaves $\mathrm{C} 2$ and $\mathrm{C} 4$ and activates C3 [51]. Increased complement C4 levels are detected in cerebrospinal fluid [52] and in 
the superior temporal gyrus, dorsolateral prefrontal and parietal cortex [53] of schizophrenia patients. In the midbrain of schizophrenia patients, positive associations are detected between complement $\mathrm{C} 1 \mathrm{qA}$ and $\mathrm{C} 3$ transcripts and markers of microglial or astrocytic functions [54].

Moreover, we detected that circulating IgA C1q CICs are significantly associated with IgM responses to Gram-negative bacteria, including $K$. pneumoniae. Gram-negative bacteria may activate the complement classical pathway, which requires antibody binding to bacterial antigens, and the alternative pathway through antibody-independent mechanism [55,56]. For example, the outer membrane proteins of $K$. pneumoniae (including porins) may bind $\mathrm{C} 1 \mathrm{q}$, via an antibody-independent process, thereby activating the complement classical pathway [55]. Complement activation plays a key role in the defense against pathogens through proteolytic cascades, the membrane attack complex, and inflammatory responses, which all help to eradicate invading microorganisms [51,57].

Nevertheless, complement activation may lead to widespread IRS activation and may consequently access the brain through breakdown of the BBB [58], a phenomenon described in schizophrenia [25]. In the brain, C1q tags unwanted cells and weak synapses for elimination through glial phagocytosis and, therefore, controls synapse elimination and, consequently, C1qderived synaptic loss may drive neurodegenerative processes [59]. Since schizophrenia is accompanied by synapse loss in the dorsolateral prefrontal cortex [60] it is tempting to speculate that increased Clq may be involved in synaptic loss. It is interesting to note that $\mathrm{C} 1 \mathrm{q}$ triggers synaptic loss especially in the early phase of neurodegenerative disorders $[58,61]$, which would be consistent with our findings of increased C1q CICs in FES, but not MES. Interestingly, C1q may play a causal role in multiple sclerosis where complement is activated around the lesions, and in Alzheimer's disease where complement is detected in tangles and plaques [58]. C1q blocking may attenuate the number of phagocytic microglia and synaptic elimination thereby improving hippocampal functions [62].

Moreover, high levels of C1q CICs in the vascular structure coupled with activation of the complement cascade and binding of $\mathrm{Clq}$ complement to the antigen-antibody molecules can result in an immune complex disease state with tissue damage as can be observed in some inflammatory and autoimmune disorders [63,64]. IgA CICs, including C1q complexes, are more pathogenic than IgM or IgG immune complexes. For example, in IgA nephropathy, $\operatorname{IgA}$ immunodeposits in kidney tissues are more dominant than the $\operatorname{IgM}$ or $\operatorname{IgG}$ complexes $[65,66]$ and C1q deposition is a critical risk factor of poor renal prognosis [67].

Moreover, it is important to note that FES is accompanied by lowered antioxidant defenses and that lowered PON1 activity coupled with increased IgA to $K$. pneumoniae determines to a large extent the BCPS-worsening in FES. PON1 has strong antioxidant and antiinflammatory properties and hydrolyzes N-(3-oxo-dodecanoyl)-homoserine lactone, a quorumsensing molecule, thereby attenuating biofilm formation and virulence of many bacteria [68]. Thus, lowered PON1 activity may aggravate the effects of $K$. pneumoniae and other opportunistic Gram-negative pathogens on Clq CIC formation in FES. Moreover, increased translocation of Gram-negative bacteria may induce immune activation and OSTOX through stimulation of the Toll Like Receptor (TLR)-4 complex and the TLR radical cycle [69].

All in all, our results indicate that that increased translocation of Gram-negative bacteria following damage to adherens junctions and the vascular barriers and lowered PON1 activity may drive increased $\mathrm{C} 1 \mathrm{q}$ CIC formation and consequent non-resolving inflammation in FES. 
The third major finding of this study is that both MES subgroups (with and without worsening) are biologically quite different phenotypes. Thus, MES with worsening is characterized by significant increases in leaky gut, immune activation, neurotoxicity, TNF- $\alpha$, IL10, and OSTOX, and lowered IgM to OSEs and antioxidant defenses, which are largely related to PON1 activity. Moreover, patients with MES with worsening show increased levels of neurotoxic TRYCATs, MIP, and IL-6 as compared with healthy controls, indicating strongly elevated neurotoxicity. Furthermore, immune activation, neurotoxicity, OSTOX, and IgA to $K$. pneumoniae impact the BCPS-worsening in MES, whereas antioxidant levels are protective. Moreover, increased IgA to K. pneumoniae was the single best predictor of residual psychotic symptoms in MES.

Natural IgM responses to OSEs are, together with PON1 activity, another part of the innate immune system [68]. Natural IgM to OSEs display antioxidant and anti-inflammatory housekeeping effects by clearing cell debris, antimicrobial activities by eliminating invading infectious particles, and anti-autoimmune effects by suppressing IgG responses [27]. All in all, our results show that lowered natural IgM and PON1 activity is accompanied by increased immune and oxidative neurotoxicity causing incremental BCPS-worsening or the deficit syndrome in MES (see Figure 4). By inference, it appears that the BCPS-deficit in schizophrenia may be caused via two different pathways: the first mechanism in FES is associated with leaky gut and $K$. pneumoniae; and the second in MES is associated with lowered IgM to OSE and PON1 activity and increased neurotoxicity.

Finally, the number of psychotic episodes was an independent predictor suggesting that factors associated with the acute episodes may further deteriorate the condition. We already showed in the 1990ties that acute episode of schizophrenia is accompanied by immune activation and an acute phase or inflammatory response $[16,17,19,20]$.

\section{Limitations}

The results of this paper should be discussed regarding its limitations. First, our study used a cross-sectional design which does not allow to establish firm causal associations. Second, it would have been even more interesting if we had measured $\mathrm{T}$ regulatory (Treg) functions as established using flow cytometric methods and different CD markers [70]. The latter study showed that acute mania episodes are accompanied by progressive deficits in Treg or CIRS functions which may further increase IRS and neurotoxicity. Third, the study included a relatively small number of FES patients and therefore the results deserve replication in larger studies including those using a prospective design.

\section{Summary}

FES is characterized by a breakdown of adherens junctions, bacterial translocation, and C1q CIC formation, whereas MES is characterized by immune activation and OSTOX. The BCPS-worsening indices in FES and MES are affected by different pathways thereby defining subgroups, namely FES and MES with and without BCPS-worsening. The results show that the post-psychotic stable phases of FES and MES are accompanied by active immune-mediated processes, and that increased load of $K$. pneumoniae may play a role in the maintenance of residual psychotic symptoms. These pathogens and associated pathways are, therefore, new drug targets to treat FES, MES, and to minimize BCPS-worsening and residual psychotic symptoms. The new drug targets delineated in FES are C1q CIC formation, breakdown of adherens junctions, and increased bacterial translocation, especially that of $K$. pneumoniae. New drug 
targets in MES are neurotoxic immune and oxidative stress pathways as well as increased $K$. pneumoniae load.

Acknowledgement

This research has been supported by the Asahi Glass Foundation, Chulalongkorn University Centenary Academic Development Project.

Conflict of interest

The authors have no conflict of interest with any commercial or other association in connection with the submitted article.

Author's contributions

All the contributing authors have participated in the manuscript. MM and BK designed the study. BK recruited patients and completed diagnostic interviews and rating scales measurements. MM carried out the statistical analyses. SS and DC performed the biomarker assays. All authors contributed to interpretation of the data and writing of the manuscript.

\section{References}

1. Maes M, Vojdani A, Galecki P, Kanchanatawan B (2020) How to Construct a Bottom-Up Nomothetic Network Model and Disclose Novel Nosological Classes by Integrating Risk Resilience and Adverse Outcome Pathways with the Phenome of Schizophrenia. Brain Sci 10(9):645. doi: 10.3390/brainsci10090645. PMID: 32957709; PMCID: PMC7565440.

2. Almulla AF, Al-Hakeim HK, Maes M (2020) Schizophrenia phenomenology revisited: positive and negative symptoms are strongly related reflective manifestations of an underlying single trait indicating overall severity of schizophrenia. CNS Spectr 20:1-10. doi: 10.1017/S1092852920001182. Epub ahead of print. PMID: 32431263.

3. Maes M, Vojdani A, Geffard M, Moreira EG, Barbosa DS, Michelin AP, Semeão LO, Sirivichayakul S, Kanchanatawan B (2019) Schizophrenia phenomenology comprises a bifactorial general severity and a single-group factor, which are differently associated with neurotoxic immune and immune-regulatory pathways. Biomol Concepts 10(1):209-225.

4. Maes M, Kanchanatawan B (2020) A Generalized Cognitive Decline (GCoDe) Partly Mediates the Effects of Neuro-Immune and Neuro-Oxidative Toxicity on the Symptomatome and Lowered Quality of Life in (Deficit) Schizophrenia. Preprints 2020110523 (doi: 10.20944/preprints202011.0523.v1).

5. Kanchanatawan B, Sriswasdi S, Maes M (2019) Supervised machine learning to decipher the complex associations between neuro-immune biomarkers and quality of life in schizophrenia. Metab Brain Dis 34(1):267-282. doi: 10.1007/s11011-018-0339-7. PMID: 30467771.

6. Kanchanatawan B, Thika S, Anderson G, Galecki P, Maes M (2018) Affective symptoms in schizophrenia are strongly associated with neurocognitive deficits indicating disorders in 
executive functions, visual memory, attention and social cognition. Prog Neuropsychopharmacol Biol Psychiatry 80(Pt C):168-176.

7. Maes M, Sirivichayakul S, Matsumoto AK, Michelin AP, de Oliveira Semeão L, de Lima Pedrão JV, Moreira EG, Barbosa DS, Carvalho AF, Solmi M, Kanchanatawan B (2020) Lowered Antioxidant Defenses and Increased Oxidative Toxicity Are Hallmarks of Deficit Schizophrenia: a Nomothetic Network Psychiatry Approach. Mol Neurobiol 57(11):4578-4597.

8. CANTAB (2018) The most validated cognitive research software. http://www.cambridgecognition.com/cantab/ October 1, 2018.

9. CERAD (1986) CERAD - An Overview: The Consortium to Establish a Registry for Alzheimer's Disease. 1986; http://cerad.mc.duke.edu/

10. Kanchanatawan B, Hemrungrojn S, Thika S, Sirivichayakul S, Ruxrungtham K, Carvalho AF, Geffard M, Anderson G, Maes M (2018) Changes in Tryptophan Catabolite (TRYCAT) Pathway Patterning Are Associated with Mild Impairments in Declarative Memory in Schizophrenia and Deficits in Semantic and Episodic Memory Coupled with Increased FalseMemory Creation in Deficit Schizophrenia. Mol Neurobiol 55(6):5184-5201.

11. WHO (1993) Study protocol for the World Health Organization project to develop a Quality of Life assessment instrument (WHOQOL). Qual Life Res 2(2):153-159.

12. Kanchanatawan B, Sriswasdi S, Thika S, Sirivichayakul S, Carvalho AF, Geffard M, Kubera M, Maes M (2018) Deficit schizophrenia is a discrete diagnostic category defined by neuroimmune and neurocognitive features: results of supervised machine learning. Metab Brain Dis 33(4):1053-1067.

13. Kanchanatawan B, Sriswasdi S, Thika S, Stoyanov D, Sirivichayakul S, Carvalho AF, Geffard M, Maes M (2018) Towards a new classification of stable phase schizophrenia into major and simple neuro-cognitive psychosis: Results of unsupervised machine learning analysis. J Eval Clin Pract 24(4):879-891.

14. Kanchanatawan B, Maes M (2018) The Effects of Tryptophan Catabolites on Negative Symptoms and Deficit Schizophrenia are Partly Mediated by Executive Impairments: Results of Partial Least Squares Path Modeling. CNS Neurol Disord Drug Targets 17(6):473-486.

15. Kirkpatrick B, Buchanan RW, McKenney PD, Alphs LD, Carpenter WT Jr (1989) The Schedule for the Deficit syndrome: an instrument for research in schizophrenia. Psychiatry Res 30(2):119-123.

16. Smith RS, Maes M (1995) The macrophage-T-lymphocyte theory of schizophrenia: additional evidence. Med Hypotheses 45(2):135-141. doi: 10.1016/0306-9877(95)90062-4. PMID: 8531836. 
17. Maes M, Delange J, Ranjan R, Meltzer HY, Desnyder R, Cooremans W, Scharpé S (1997) Acute phase proteins in schizophrenia, mania and major depression: modulation by psychotropic drugs. Psychiatry Res 66(1):1-11. doi: 10.1016/s0165-1781(96)02915-0. PMID: 9061799.

18. Roomruangwong C, Noto C, Kanchanatawan B, Anderson G, Kubera M, Carvalho AF, Maes M (2020) The Role of Aberrations in the Immune-Inflammatory Response System (IRS) and the Compensatory Immune-Regulatory Reflex System (CIRS) in Different Phenotypes of Schizophrenia: the IRS-CIRS Theory of Schizophrenia. Mol Neurobiol 57(2):778-797. doi: 10.1007/s12035-019-01737-z. Epub 2019 Aug 31. PMID: 31473906.

19. Maes M, Meltzer HY, Bosmans E (1994) Immune-inflammatory markers in schizophrenia: comparison to normal controls and effects of clozapine. Acta Psychiatr Scand 89(5):346-351. doi: 10.1111/j.1600-0447.1994.tb01527.x. PMID: 8067274.

20. Maes M, Meltzer HY, Buckley P, Bosmans E (1995) Plasma-soluble interleukin-2 and transferrin receptor in schizophrenia and major depression. Eur Arch Psychiatry Clin Neurosci 244(6):325-329. doi: 10.1007/BF02190412. PMID: 7772617.

21. Noto C, Ota VK, Gouvea ES, Rizzo LB, Spindola LM, Honda PH, Cordeiro Q, Belangero SI, Bressan RA, Gadelha A, Maes M, Brietzke E (2014) Effects of risperidone on cytokine profile in drug-naïve first-episode psychosis. Int $\mathrm{J}$ Neuropsychopharmacol 18(4):pyu042. doi: 10.1093/ijnp/pyu042. PMID: 25522386; PMCID: PMC4360233.

22. Maes M, Sirivichayakul S, Matsumoto AK, Maes A, Michelin AP, de Oliveira Semeão L, de Lima Pedrão JV, Moreira EG, Barbosa DS, Geffard M, Carvalho AF, Kanchanatawan B (2020) Increased Levels of Plasma Tumor Necrosis Factor- $\alpha$ Mediate Schizophrenia Symptom Dimensions and Neurocognitive Impairments and Are Inversely Associated with Natural IgM Directed to Malondialdehyde and Paraoxonase 1 Activity. Mol Neurobiol 57(5):2333-2345. doi: 10.1007/s12035-020-01882-w. Epub 2020 Feb 10. PMID: 32040834.

23. Sirivichayakul S, Kanchanatawan B, Thika S, Carvalho AF, Maes M (2019) Eotaxin, an Endogenous Cognitive Deteriorating Chemokine (ECDC), Is a Major Contributor to Cognitive Decline in Normal People and to Executive, Memory, and Sustained Attention Deficits, Formal Thought Disorders, and Psychopathology in Schizophrenia Patients. Neurotox Res 35(1):122138.

24. Sirivichayakul S, Kanchanatawan B, Thika S, Carvalho AF, Maes M (2019) A New Schizophrenia Model: Immune Activation is Associated with the Induction of Different Neurotoxic Products Which Together Determine Memory Impairments and Schizophrenia Symptom Dimensions. CNS Neurol Disord Drug Targets 18(2):124-140.

25. Maes M, Sirivichayakul S, Kanchanatawan B, Vodjani A (2019) Upregulation of the Intestinal Paracellular Pathway with Breakdown of Tight and Adherens Junctions in Deficit Schizophrenia. Mol Neurobiol 56(10):7056-7073. doi: 10.1007/s12035-019-1578-2. Epub 2019 Apr 10. PMID: 30972627. 
26. Guidara W, Messedi M, Naifar M, Maalej M, Grayaa S, Omri S, Ben Thabet J, Maalej M, Charfi N, Ayadi F (2020) Predictive value of oxidative stress biomarkers in drug-free patients with schizophrenia and schizo-affective disorder. Psychiatry Res 293:113467. doi: 10.1016/j.psychres.2020.113467. Epub 2020 Sep 20. PMID: 33198042.

27. Maes M, Kanchanatawan B, Sirivichayakul S, Carvalho AF (2019) In Schizophrenia, Deficits in Natural IgM Isotype Antibodies Including Those Directed to Malondialdehyde and Azelaic Acid Strongly Predict Negative Symptoms, Neurocognitive Impairments, and the Deficit Syndrome. Mol Neurobiol 2019 56(7):5122-5135. doi: 10.1007/s12035-018-1437-6. Epub 2018 Nov 27. PMID: 30484113.

28. Maes M, Sirivichayakul S, Kanchanatawan B, Vodjani A (2019) Breakdown of the Paracellular Tight and Adherens Junctions in the Gut and Blood Brain Barrier and Damage to the Vascular Barrier in Patients with Deficit Schizophrenia. Neurotox Res 36(2):306-322.

29. Noto MN, Maes M, Nunes SOV, Ota VK, Rossaneis AC, Verri WA Jr, Cordeiro Q, Belangero SI, Gadelha A, Bressan RA, Noto C (2019) Activation of the immune-inflammatory response system and the compensatory immune-regulatory system in antipsychotic naive first episode psychosis. Eur Neuropsychopharmacol 29(3):416-431. doi: 10.1016/j.euroneuro.2018.12.008. Epub 2018 Dec 26. PMID: 30594344.

30. Trovão N, Prata J, VonDoellinger O, Santos S, Barbosa M, Coelho R (2019) Peripheral Biomarkers for First-Episode Psychosis-Opportunities from the Neuroinflammatory Hypothesis of Schizophrenia. Psychiatry Investig 16(3):177-184. doi: 10.30773/pi.2018.12.19.1. Epub 2019 Mar 7. PMID: 30836740; PMCID: PMC6444098.

31. Dzikowski M, Juchnowicz D, Dzikowska I, Rog J, Próchnicki M, Kozioł M, KarakulaJuchnowicz H (2020) The Differences between Gluten Sensitivity, Intestinal Biomarkers and Immune Biomarkers in Patients with First Episode and Chronic Schizophrenia. J Clin Med 9(11):3707. doi: 10.3390/jcm9113707. PMID: 33218214 ; PMCID: PMC7699286.

32. Kittirathanapaiboon P, Khamwongpin M (2005) The Validity of the Mini International Neuropsychiatric Interview (M.I.N.I.) Thai Version: Suanprung Hospital, Department of Mental Health.

33. Kay SR, Fiszbein A, Opler LA (1986) Negative Symptom Rating Scale: limitations in psychometric and research methodology. Psychiatry Res 19(2):169-173.

34. Andreasen NC (1989) The Scale for the Assessment of Negative Symptoms (SANS): conceptual and theoretical foundations. Brit J Psychiatry Suppl 7:49-58.

35. Overall JE, Gorham DR (1962) The brief psychiatric rating scale. Psychological Reports 10:799-812

36. Hamilton M (1960) A rating scale for depression. J Neurol Neurosurg Psychiatry 23:56-62. 
37. Roomruangwong C, Carvalho AF, Geffard M, Maes M (2019) The menstrual cycle may not be limited to the endometrium but also may impact gut permeability. Acta Neuropsychiatr 31(6):294-304. doi: 10.1017/neu.2019.30. Epub 2019 Oct 14. PMID: 31364524.

38. Benjamini Y, Hochberg Y (1995) Controlling the false discovery rate: a practical and powerful approach to multiple testing. J Royal Statistics Soc Series b (Methodological) 57:289300 .

39. Rosen K, Garety P (2005) Predicting recovery from schizophrenia: a retrospective comparison of characteristics at onset of people with single and multiple episodes. Schizophr Bull 31(3):735-750. doi: 10.1093/schbul/sbi017. Epub 2005 Feb 16. PMID: 16123527.

40. Aberle H, Schwartz H, Kemler R (1996) Cadherin-catenin complex: protein interactions and their implications for cadherin function. J Cell Biochem 61(4):514-23. doi: 10.1002/(SICI)10974644(19960616)61:4\%3C514::AID-JCB4\%3E3.0.CO;2-R. PMID: 8806074.

41. Gooding JM, Yap KL, Ikura M (2004) The cadherin-catenin complex as a focal point of cell adhesion and signalling: new insights from three-dimensional structures. Bioessays 26(5):497511. doi: 10.1002/bies.20033. PMID: 15112230.

42. Vojdani A, Vojdani E (2019) Food-associated autoimmunities: when food turns your immune system against you. In press.

43. Guo L, Zhang H, Hou Y, Wei T, Liu J (2016) Plasmalemma vesicle-associated protein: A crucial component of vascular homeostasis. Exp Ther Med 12(3):1639-1644. doi: 10.3892/etm.2016.3557. Epub 2016 Jul 27. PMID: 27602081; PMCID: PMC4998186.

44. Bodey GP, Elting LS, Rodriquez S, Hernandez M. Klebsiella bacteremia (1989) A 10-year review in a cancer institution. Cancer 64(11):2368-2376. doi: 10.1002/10970142(19891201)64:1. PMID: 2804929.

45. García de la Torre M, Romero-Vivas J, Martínez-Beltrán J, Guerrero A, Meseguer M, Bouza E (1985) Klebsiella bacteremia: an analysis of 100 episodes. Rev Infect Dis 7(2):143-50. doi: 10.1093/clinids/7.2.143. PMID: 3890094.

46. Williams P, Ciurana B, Camprubi S, Tomas JM (1990) Influence of lipopolysaccharide chemotype on the interaction between Klebsiella pneumoniae and human polymorphonuclear leucocytes. FEMS Microbiol Lett 57(3):305-309. doi: 10.1016/0378-1097(90)90085-5. PMID: 1698690 .

47. Bengoechea JA, Sa Pessoa J (2019) Klebsiella pneumoniae infection biology: living to counteract host defences. FEMS Microbiol Rev 43(2):123-144. doi: 10.1093/femsre/fuy043. PMID: 30452654; PMCID: PMC6435446. 
48. Costa AM, Leite M, Seruca R, Figueiredo C (2013) Adherens junctions as targets of microorganisms: a focus on Helicobacter pylori. FEBS Lett 587(3):259-265. doi: 10.1016/j.febslet.2012.12.008. Epub 2012 Dec 19. PMID: 23262219.

49. Vikström E, Bui L, Konradsson P, Magnusson KE (2009) The junctional integrity of epithelial cells is modulated by Pseudomonas aeruginosa quorum sensing molecule through phosphorylation-dependent mechanisms. Exp Cell Res 315(2):313-326. doi: 10.1016/j.yexcr.2008.10.044. Epub 2008 Nov 12. PMID: 19038248.

50. Lubkin A, Torres VJ (2017) Bacteria and endothelial cells: a toxic relationship. Curr Opin Microbiol 35:58-63. doi: 10.1016/j.mib.2016.11.008. Epub 2016 Dec 22. PMID: 28013162; PMCID: PMC5481510.

51. Dunkelberger JR, Song WC (2010) Complement and its role in innate and adaptive immune responses. Cell Res 20(1):34-50. doi: 10.1038/cr.2009.139. Epub 2009 Dec 15. PMID: 20010915.

52. Gallego JA, Blanco EA, Morell C, Lencz T, Malhotra AK (2020) Complement component $\mathrm{C} 4$ levels in the cerebrospinal fluid and plasma of patients with schizophrenia. Neuropsychopharmacology 22. doi: 10.1038/s41386-020-00867-6. Epub ahead of print. PMID: 32961544.

53. Rey R, Suaud-Chagny MF, Bohec AL, Dorey JM, d'Amato T, Tamouza R, Leboyer M (2020) Overexpression of complement component $\mathrm{C} 4$ in the dorsolateral prefrontal cortex, parietal cortex, superior temporal gyrus and associative striatum of patients with schizophrenia. Brain Behav Immun 90:216-225. doi: 10.1016/j.bbi.2020.08.019. Epub 2020 Aug 19. PMID: 32827700 .

54. Purves-Tyson TD, Robinson K, Brown AM, Boerrigter D, Cai HQ, Weissleder C, Owens SJ, Rothmond DA, Shannon Weickert C (2020) Increased Macrophages and C1qA, C3, C4 Transcripts in the Midbrain of People with Schizophrenia. Front Immunol 11:2002. doi: 10.3389/fimmu.2020.02002. PMID: 33133060; PMCID: PMC7550636.

55. Albertí S, Marqués G, Camprubí S, Merino S, Tomás JM, Vivanco F, Benedí VJ (1993) C1q binding and activation of the complement classical pathway by Klebsiella pneumoniae outer membrane proteins. Infect Immun 61(3):852-860. doi: 10.1128/IAI.61.3.852-860.1993. PMID: 8432605; PMCID: PMC302811.

56. Heesterbeek DAC, Angelier ML, Harrison RA, Rooijakkers SHM (2018) Complement and Bacterial Infections: From Molecular Mechanisms to Therapeutic Applications. J Innate Immun. 10(5-6):455-464. doi: 10.1159/000491439. Epub 2018 Aug 27. PMID: 30149378; PMCID: PMC6784045.

57. Paczosa MK, Mecsas J (2016) Klebsiella pneumoniae: Going on the Offense with a Strong Defense. Microbiol Mol Biol Rev 15;80(3):629-661. doi: 10.1128/MMBR.00078-15. PMID: 27307579 ; PMCID: PMC4981674. 
58. Morgan BP (2018) Complement in the pathogenesis of Alzheimer's disease. Semin Immunopathol 40(1):113-124. doi: 10.1007/s00281-017-0662-9. Epub 2017 Nov 13. Erratum in: Semin Immunopathol. 2018 Sep 21; PMID: 29134267 ; PMCID: PMC5794825.

59. Eroglu C, Barres BA (2010) Regulation of synaptic connectivity by glia. Nature 11;468(7321):223-231. doi: 10.1038/nature09612. PMID: 21068831; PMCID: PMC4431554.

60. Glantz LA, Lewis DA (2000) Decreased dendritic spine density on prefrontal cortical pyramidal neurons in schizophrenia. Arch Gen Psychiatry 57(1):65-73. doi: 10.1001/archpsyc.57.1.65. PMID: 10632234.

61. Cho K (2019) Emerging Roles of Complement Protein C1q in Neurodegeneration. Aging Dis 10(3):652-663. doi: 10.14336/AD.2019.0118. PMID: 31165008; PMCID: PMC6538225.

62. Hong S, Beja-Glasser VF, Nfonoyim BM, Frouin A, Li S, Ramakrishnan S, Merry KM, Shi Q, Rosenthal A, Barres BA, Lemere CA, Selkoe DJ, Stevens B (2016) Complement and microglia mediate early synapse loss in Alzheimer mouse models. Science 352(6286):712-716. doi: 10.1126/science.aad8373. Epub 2016 Mar 31. PMID: 27033548; PMCID: PMC5094372.

63. Espinoza LR, Osterland CK (1983) "Circulating Immune Complexes. Their Clinical Significance.” Futt, Publishing Co., NY, pp 1-319.

64. Abrass CK, Border WA, Glassock RJ (1980) Circulating immune complexes in rats with autologous immune complex nephritis. Lab Invest 43(1):18-27. PMID: 6446622.

65. Vizjak A, Ferluga D, Rozic M, Hvala A, Lindic J, Levart TK, Jurcić V, Jennette JC (2008) Pathology, clinical presentations, and outcomes of C1q nephropathy. J Am Soc Nephrol 19(11):2237-2244. doi: 10.1681/ASN.2007080929. Epub 2008 Jul 23. PMID: 18650484; PMCID: PMC2573004.

66. Rizk DV, Maillard N, Julian BA, Knoppova B, Green TJ, Novak J, Wyatt RJ (2019) The Emerging Role of Complement Proteins as a Target for Therapy of IgA Nephropathy. Front Immunol 10:504. doi: 10.3389/fimmu.2019.00504. PMID: 30941137; PMCID: PMC6433978.

67. Lee HJ, Choi SY, Jeong KH, Sung JY, Moon SK, Moon JY, Lee SH, Lee TW, Ihm CG (2013) Association of C1q deposition with renal outcomes in IgA nephropathy. Clin Nephrol 80(2):98-104. doi: 10.5414/CN107854. PMID: 23587123.

68. Matsumoto AK, Maes M, Supasitthumrong T, Maes A, Michelin AP, de Oliveira Semeão L, de Lima Pedrão JV, Moreira EG, Kanchanatawan B, Barbosa DS (2020) Deficit schizophrenia and its features are associated with PON1 Q192R genotypes and lowered paraoxonase 1 (PON1) enzymatic activity: effects on bacterial translocation. CNS Spectr 23:1-10. doi: 10.1017/S1092852920001388. Epub ahead of print. PMID: 32638685. 
30

69. Lucas K, Maes M (2013) Role of the Toll Like receptor (TLR) radical cycle in chronic inflammation: possible treatments targeting the TLR4 pathway. Mol Neurobiol 48(1):190-204. doi: 10.1007/s12035-013-8425-7. Epub 2013 Feb 26. PMID: 23436141; PMCID: PMC7091222.

70. Maes M, Nani JV, Noto C, Rizzo L, Hayashi MAF, Brietzke E (2021) Impairments in Peripheral Blood T Effector and T Regulatory Lymphocytes in Bipolar Disorder Are Associated with Staging of Illness and Anti-cytomegalovirus IgG Levels. Mol Neurobiol 58(1):229-242. doi: 10.1007/s12035-020-02110-1. Epub 2020 Sep 11. PMID: 32914395. 